\title{
Phytoplasmes et phytoplasmoses
}

\author{
MT Cousin
}

\author{
INRA, station de pathologie végétale, route de Saint-Cyr, F-78026 Versailles cedex, France
}

(Reçu le 6 mars 1995; accepté le 3 juillet 1995)

\begin{abstract}
Résumé - Les récents progrès concernant la connaissance de la fraction 16S et de l'espaceur 16S-23S de l'ADN ribosomique ont mis en évidence les particularités des micro-organismes anciennement désignés sous l'appellation "Mycoplasma-like organisms : MLOs" et justifié la nouvelle dénomination «phytoplasmes" choisie par le Comité de taxonomie des mollicutes de l'«International Organization for Mycoplasmology (IOM)». Les principaux caractères des phytoplasmes permettant leur classification au sein des bactéries et des virus sont décrits. La méthode PAUP (Phylogenetic analysis using parcimony) a été appliquée à la fraction $16 \mathrm{~S}$ et à l'espaceur intergénique 16S-23S de I'ADN ribosomique afin d'établir la position phylogénétique des phytoplasmes parmi les bactéries. Ultérieurement, des tentatives de classification des différentes maladies à phytoplasmes ont été entreprises d'abord en utilisant le polymorphisme des fragments de I'ADN ribosomique amplifiés par des amorces universelles de phytoplasmes. Puis, la connaissance des séquences de la fraction $16 \mathrm{~S}$ et de l'espaceur intergénique 16S-23S a permis d'établir un arbre phylogénétique des phytoplasmes en utilisant la méthode PAUP. Plusieurs groupes ont ainsi été caractérisés. De grands progrès concernant la sensibilité et la spécificité des méthodes de diagnostic résultent de la connaissance des ADN ribosomique et génomique et des antigènes. On dispose désormais d'une panoplie de techniques qu'il convient d'adapter aux fins recherchées, inventaire ou épidémiologie et à la teneur en phytoplasmes des espèces végétales à
\end{abstract}

Liste des abréviations. AAY ou Ay-Mi : aster yellow (États-Unis). ACLR : enroulement chlorotique de l'abricotier, apricot chlorotic leafroll (France). AT : prolifération du pommier, apple proliferation (France). ASHY : jaunisse du frêne, ash yellow (États-Unis). Ash-Ger : jaunisse du frêne, ash yellow (Allemagne). AV 2192 : aster yellow (Allemagne). AY gl : germes fins du glaieul, gladiolus aster yellow (France). Ay-Jpn : aster yellow (Japon). Ay-Mi ou AAY : aster yellow (Floride). BAWB : balai de sorcière de l'aune noir, black alder witches' broom. BLL : maladie des petites feuilles de l'aubergine ou brinjal little leaf. BLTVA ou Bltva ou BVK : phytoplasme de la virescence de la betterave transmis par cicadelle, beet leafhopper transmitted virescence agent. CP ou KV : phyllodie du trèfle, clover phyllody.CRP : phyllodie observée à l'état naturel sur Catharanthus roseus au Soudan. CSP : phyllodie de Crotalaria saltiana, Crotalaria saltiana phyllody (Soudan). EYK : jaunisse de l'orme, elm yellow. FBP : phyllodie de la féverole, faba bean phyllody (Soudan). FD ou fd: flavescence dorée de la vigne, golden flavescence of vine (France). FDI ou FDU ou GYU : jaunisse de la vigne ou grapevine yellows of Udine (Italie). Jujube-ch : balai de sorcière du jujubier, jujube witches' broom (Chine). KV ou CP : phyllodie du trèfle, clover phyllody. LY : jaunisse létale du palmier à huile, lethal yellowing of coconut palm.Lyps-FI : phytoplasmose de la tomate ou Lycopersicon. MOL : maladie de Molières du cerisier, Molières' disease (France).MLO I : aster yellow de l'oignon, onion aster yellow. MLO II : balai de sorcière du tsuwabuki, tsuwabuki witches' broom. MLO III : nanisme jaune du riz, rice yellow dwarf. OAY : aster yellow d'oenothera (États-Unis). PD : dépérissement du poirier, pear decline. Peach $X$ disease : maladie $X$ du pêcher. PER : jaunisse du pêcher. PLN : leptonécrose du prunier, plum leptonecrosis. PPER : jaunisse des fruits à noyaux européens. Ppwb-Ch : prunus persica witches' broom, balai de sorcière de Prunus persica (Chine). PWB : balai de sorcière du peuplier, poplar witches' broom (France). PYLR : enroulement à feuilles jaunes du pêcher, peach yellow leafroll. Pylr1-Ca ou PYLR1 : enroulement à feuilles jaunes du pêcher, peach yellow leafroll (isolat 1) (États-Unis). Pylr2-Ca ou PYLR2 : enroulement à feuilles jaunes du pêcher, peach yellow leafroll (isolat 2) (États-Unis). SUNHphyl : phyllodie du chanvre du Bengale ou Crotalaria juncea, sunnhemp phyllody (Thaïlande). SUNH ou SUNHP ou SUNHwb : balai de sorcière du chanvre du Bengale ou Crotalaria juncea, sunnhemp witches' broom (Thaillande). SAS : sandal spike (Inde). SAY : severe aster yellow (États-Unis). SCWL : maladie des feuilles blanches de la canne à sucre, sugar cane white leaf (Thaïlande).SES : phyllodie du sésame, sesame phyllody (Thaïlande). SOY : phyllodie du soja, soybean phyllody (Thaïlande). STOL : stolbur. TBB : maladie des gros bourgeons de la tomate, tomato big bud (Australie). ULW : balai de sorcière de l'orme ou ulmus, elm witches' broom. VAC : balai de sorcière de la myrtille, vaccinium witches' broom. VK ou BN : bois noir, jaunisse de la vigne (France), Vergilbungskrankeit (Allemagne), grapevine yellows. WX : western X du pêcher et du cerisier (États-Unis). YDL : dépérissement jaune du lavandin, yellow decline of lavender (France). 
l'étude, espèces herbacées ou ligneuses. La connaissance des insectes vecteurs, de leurs cycles et des plantes réservoirs conditionnent la lutte contre ces maladies. Dans le cas de plantes multipliées végétativement, essences ligneuses en particulier, l'amélioration sanitaire du matériel de base par différentes méthodes est envisagée. Enfin, la résistance génétique constitue toujours la méthode de choix dans la lutte contre ces maladies. En l'absence de résistances naturelles, l'obtention de plantes transgéniques résistantes aux insectes ouvre de nouvelles perspectives.

\section{phytoplasme / mycoplasma-like organism / phylogénie / diagnostic}

Summary - Phytoplasmas and phytoplasma diseases. Recent progress concerning knowledge of ribosomal DNA (16S and intergenic spacer 16S-23S) has provided an increased understanding of the particularities of procaryotes previously named mycoplasma-like organisms (MLOs) and justified their new name 'phytoplasmas', which was recommended by the Subcommittee on the Taxonomy of Mollicutes of the International Organization for Mycoplasmology (IOM). The main characteristics of phytoplasmas supporting their classification among bacteria and viruses are described here. The PAUP (phylogenetic analysis using parcimony) method was applied to the 165 and intergenic 16S-23S fractions of the ribosomal DNA in order to establish the phylogenetic position of phytoplasmas among bacteria and viruses. Subsequently, attempts to classify different phytoplasmas were made, first by using the polymorphism of ribosomal DNA fractions amplified with universal phytoplasma primers. Thereafter, the knowledge of the ribosomal $16 S$ and intergenic 16S-23S DNA sequences made it possible to establish a phylogenetic tree of phytoplasmas using the PAUP method. Thus, several phytoplasma groups were characterized. Significant progress concerning the sensitivity and specificity of the diagnostic methods has been made on the basis of the studies of ribosomal and genomic DNA and antigens. A variety of techniques are available which remain to be adapted to particular purposes such as inventory and epidemiology or to original host species that tend to influence phytoplasma concentrations within infected plants such as herbaceous and woody species. The control of phytoplasma diseases depends on a better knowledge of the insect vectors, their life cycles and reservoirs. In the case of vegetatively propagated host plant species, especially woody species, sanitary improvement of the genitor plants through different methods is available. Finally, breeding for resistance is always the recommended method for the control of phytoplasma diseases. When this resistance is not present in natural conditions, transgenic plants resistant to insect vectors may be a promising way to control the diseases.

phytoplasma / mycoplasma-like organism / phylogeny / diagnosis

\section{INTRODUCTION. UNE NOUVELLE DÉNOMINATION POUR LES MLOS (MYCOPLASMALIKE-ORGANISMS) : «PHYTOPLASMES»}

En juillet 1994, le Comité de taxonomie des mollicutes décida d'adopter l'appellation «phytoplasme» en remplacement de "MLO», utilisée pendant plus de 20 ans. Les phytoplasmes sont des parasites de plantes appartenant à la classe des mollicutes (étymologiquement : micro-organismes à peau molle, dépourvus de paroi cellulaire). Contrairement aux spiroplasmes, ils n'ont jamais été cultivés en milieu acellulaire. La dénomination «MLO» avait été choisie lors de leur observation en microscopie électronique par transmission (MET), en raison de la similarité de ces agents pathogènes avec les "mycoplasmes" bien connus chez l'homme et les animaux. Les recherches concernant l'étude de l'ADN ribosomique ont considérablement progressé au cours de ces dernières années. L'étude des séquences de la fraction 16S (S, constante de sédimentation) de l'ADN ribosomique et de l'espaceur intergénique situé entre le $16 \mathrm{~S}$ et le $23 \mathrm{~S}$ fait apparaître des différences importantes entre uphyto- plasmes» et «mycoplasmes» animaux. Le Comité de taxonomie créa donc l'appellation "phytoplasmes" pour les désigner en raison de leur pathogénicité pour un grand nombre de plantes et de leurs caractéristiques génétiques uniques. Cependant, il fut objecté que cette appellation ne fournissait aucune indication sur les insectes vecteurs dans lesquels ils se multiplient également. L'appellation "phytoplasme» fut finalement conservée car ils sont essentiellement parasites de plantes et n'affectent pratiquement pas les insectes vecteurs dont seule la longévité est parfois réduite.

\section{IMPORTANCE ÉCONOMIQUE ET SYMPTÔMES DES PHYTOPLASMOSES}

Les phytoplasmoses entraînent une altération puis une destruction totale des récoltes. Elles sont préjudiciables en pays tempérés et désastreuses en pays tropicaux en raison des cycles ininterrompus des plantes adventices et des insectes vecteurs. En climat tempéré elles affectent principalement la vigne, les arbres fruitiers et les essences ligneuses utilisées en milieux 
urbain, périurbain et forestier. Les maladies à phytoplasmes commencent à être répertoriées chez une quarantaine d'essences ligneuses.

Elles présentent un certain nombre de symptômes caractéristiques affectant l'appareil reproducteur et l'appareil végétatif.

On note en particulier des altérations tératologiques : stérilité, virescence ou verdissement des pièces florales, phyllodie qui consiste en une transformation des pièces florales en lames foliacées, ainsi qu'une prolifération de certains organes, pistil et réceptacle, donnant naissance à des pousses végétatives (Cousin et al, 1986).

La coloration du feuillage est altérée. On observe le plus souvent une flavescence qui a contribué à la désignation de ces maladies sous le nom de jaunisses, en anglais "yellows". Dans le cas des essences ligneuses, les hétérogénéités de coloration, au début de l'installation de la maladie, sont particulièrement frappantes et totalement différentes d'un déséquilibre nutritionnel.

De plus, on assiste à une inhibition du bourgeon terminal et à une prolifération des bourgeons axillaires contribuant à l'aspect en balai de sorcière ou witches' broom fréquemment observé chez certaines espèces ligneuses telles que le peuplier. Ce phénomène traduit un déséquilibre hormonal encore mal connu.

Enfin, dans le cas de nombreuses espèces ligneuses, on observe le «die back» ou présence de flèches mortes. Ce symptôme et les balais de sorcières, observés principalement à la base de l'arbre, indiquent la phase terminale de la maladie qui précède la mort de l'arbre chez le peuplier (Sharma et Cousin, 1986).

Sur les ormes américains on détecte aussi une sévère nécrose du phloème suivie de la mort des arbres.

Ces symptômes, visibles sur les parties aériennes de la plante, s'accompagnent d'une modification du système racinaire. L'importance de la colonisation des racines a été mise en évidence dans le cas de nombreuses essences ligneuses, arbres fruitiers en particulier. D'autre part, en ce qui concerne Catharanthus roseus atteint de stolbur, les racines sont épaisses, courtes et l'angle d'insertion sur les racines d'ordre supérieur considérablement augmenté. Chez les légumineuses infectées, tels les trèfles atteints de phyllodie, les souches de Rhizobium ne sont plus capables de fixer l'azote atmosphérique alors que la nodulation est anormalement abondante. L'immunomarquage des antigènes à l'aide d'un antisérum polyclonal dirigé contre la flavescence dorée de la vigne (FD) a permis, conjointement avec la méthode ELISA, de suivre le trajet de la flavescence dorée dans son hôte herbacé : la féverole. On constate, $17 \mathrm{j}$ après le début de la prise de nourriture par les insectes vecteurs, que le système racinaire est envahi, et ce n'est qu'une trentaine de jours plus tard que les phytoplasmes atteignent la pousse terminale (Lherminier et al, 1994).

\section{CLASSIFICATION AU SEIN DES BACTÉRIES ET DES VIRUS (TABLEAU I)}

Les phytoplasmes appartiennent à la classe des mollicutes dépourvus de paroi cellulaire. Ils se distinguent en cela des autres bactéries à l'exception des formes $L$ qui en sont aussi dépourvues. L'absence de paroi contribue à leur polymorphisme. Ainsi, les phytoplasmes sont capables de se déformer en particulier pour franchir les pores des parois criblées du liber. Leur taille varie de $100 \mathrm{~nm}$ à plus d'un micron dans le cas de formes filamenteuses mais ils ne possèdent pas de morphologie hélicoïdale, contrairement aux spiroplasmes qui appartiennent comme eux à la famille des mollicutes. L'absence de paroi leur confère un certain nombre de critères tels que l'insensibilité aux antibiotiques du type pénicilline, actifs sur les parois bactériennes et la forte sensibilité aux variations de pression osmotique. Elle justifie leur localisation presque exclusive dans la sève des tubes criblés dont la pression osmotique atteint de 10 à 12 atmosphères. Ils sont, en revanche, sensibles aux antibiotiques du groupe des tétracyclines qui agissent sur la synthèse protéique.

La détection de phytoplasmes isolés, à la limite de la visibilité en microscopie photonique, est facilitée par l'utilisation de la lumière fluorescente.

Ce sont d'authentiques cellules possédant les 2 types d'acides nucléiques, ADN et ARN, comme l'ensemble des bactéries mais contrairement aux virus qui sont constitués seulement de l'un d'entre eux.

Comme les phytoplasmes, certaines bactéries inféodées au phloème n'ont pas encore été cultivées. Ces bactéries, qualifiées de "fastidious" (littéralement «exigeantes») par les auteurs anglophones, sont caractérisées par leur incapacité à croître dans les milieux synthétiques classiquement utilisés en bactériologie, d'où le terme de dysphagobactéries (dysphago- : difficile à nourrir) qui est proposé pour les nommer. 
Tableau I. Classification des phytoplasmes au sein des bactéries et des virus.

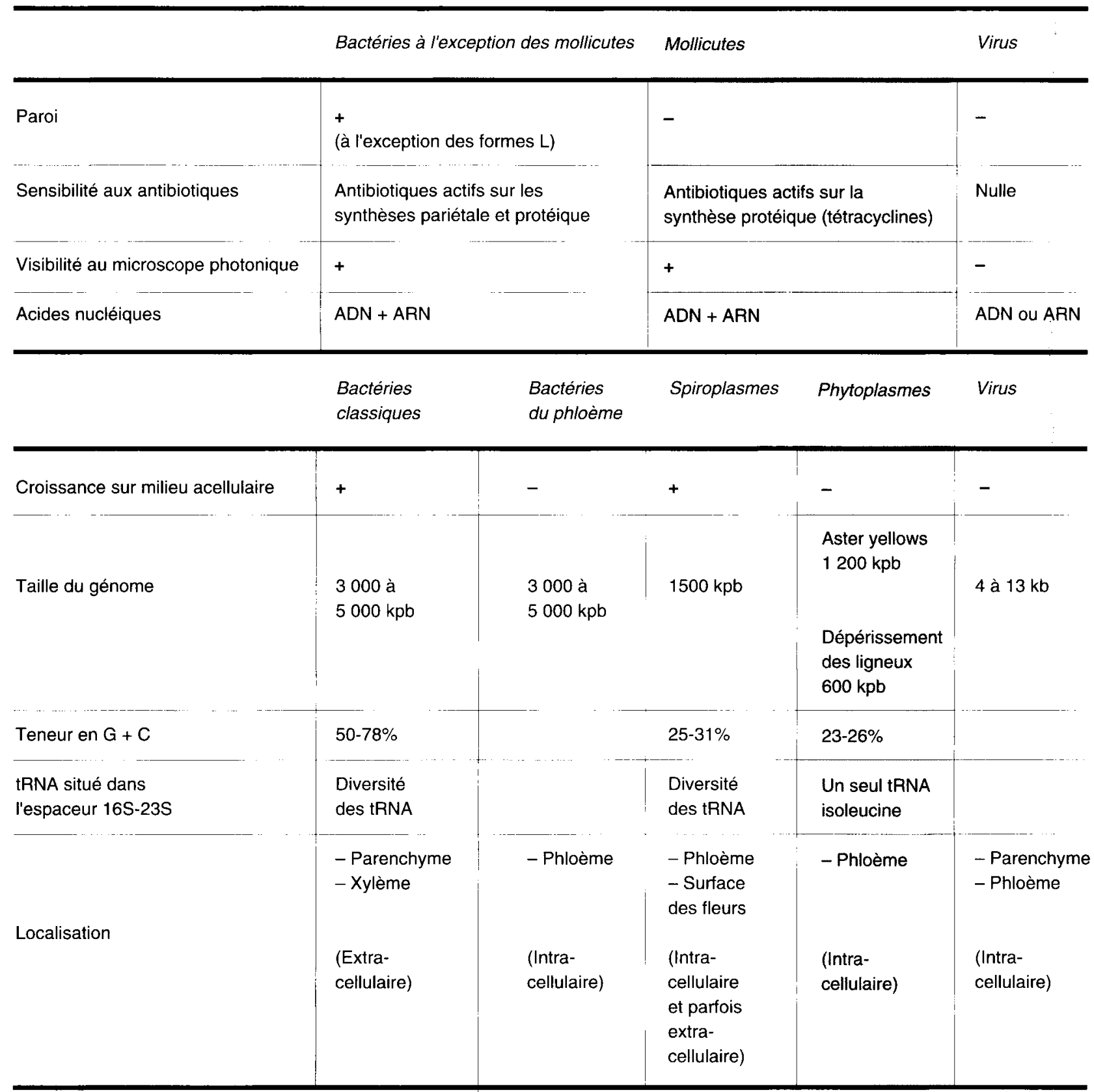

La taille de leur génome varie suivant les phytoplasmes considérés de 600 à $1200 \mathrm{kpb}$ (kilo paires de bases). Elle est la plus petite enregistrée chez des organismes pouvant se répliquer de façon autonome. La connaissance de cette taille a été obtenue avec précision grâce aux progrès réalisés par l'utilisation de la technique d'électrophorèse en champ pulsé mise au point sur phytoplasmes aux États-Unis (Neimark et Kirkpatrick, 1993). Elle permet l'observation du génome entier sur gel d'électrophorèse. Cette faible taille correspond à une évolution régressive. Les organismes les plus évolués subissent en effet une élimination progressive des séquences non codantes. On admet que le génome des aster yellows mesurant $1200 \mathrm{kpb}$, est constitué de 2 chromosomes dont un grand nombre de séquences sont communes. Au cours de l'évolution, observée en particulier dans le cas des phytoplasmes responsables du dépérissement des ligneux, seul un chromosome subsisterait.

Parmi les bactéries, les phytoplasmes ont aussi la plus faible teneur en bases $\mathrm{G}+\mathrm{C}$ (23 à $26 \%$ ) comparativement aux spiroplasmes (25 à $31 \%$ ) et surtout à l'ensemble des bactéries à l'exception des mollicutes (50 à 78\%) 
Tous les phytoplasmes possèdent, au niveau de l'espaceur 16S-23S, un gène tRNA identique : le gène tRNA isoleucine (Kirkpatrick et al, 1994). Ce caractère a contribué à leur regroupement en une famille homogène : "les phytoplasmes".

Contrairement aux spiroplasmes que I'on observe parfois à l'état saprophyte à la surface des fleurs et dont la pathogénicité n'a été mise en évidence que dans un nombre limité de cas, tous les phytoplasmes sont pathogènes et intracellulaires. Localisés le plus souvent dans les tubes criblés du phloème ils ont été parfois trouvés dans les cellules parenchymateuses du phloème, exceptionnellement dans le parenchyme cortical de féverole atteinte de phyllodie au Maroc (Cousin et al, 1970) et dans les cellules de cuscute. Autrefois confondus avec certaines bactéries du phloème dont la culture n'a pu être obtenue à ce jour, les phytoplasmes s'en distinguent aux forts grossissements du microscope électronique qui permet l'observation de la paroi de ces bactéries. En raison de leur localisation dans les tubes criblés du phloème, ils ne sont pas transmis mécaniquement. La transmission expérimentale s'effectue par greffe au sein d'une même famille ou par cuscute d'une famille à l'autre. Dans la nature, les phytoplasmes sont disséminés par les insectes vecteurs. Dans tous les cas, les tissus conducteurs doivent être atteints par l'appareil piqueur de l'insecte pour que l'infection réussisse.

\section{POSITION PHYLOGÉNÉTIQUE PARMI LES BACTÉRIES}

La position phylogénétique des phytoplasmes est essentiellement basée sur l'étude de l'ADN ribosomique qui a considérablement progressé au cours des dernières années (Deng et Hiruki, 1991). Les fractions les plus étudiées de l'ADN ribosomique furent la fraction $16 S$ et l'espaceur intergénique 16S-23S. Le séquençage de ces fractions chez un grand nombre de phytoplasmes fut à l'origine des progrès réalisés dans la connaissance de leur phylogénie.

En clonant et en séquençant la région codant pour I'ARNr 16S de phytoplasmes et de plusieurs autres bactéries et en utilisant la méthode cladistique ou de parcimonie, Lim et Sears (1989), ont montré que les phytoplasmes dérivent de Bacillus subtilis (bactérie Gram+). La méthode de parcimonie, largement utilisée dans l'étude des proximités génétiques entre souches de HIV, consiste à comparer des séquences entières, base à base. PAUP (Phylogenetic analysis using parsimony) est un programme informatique qui utilise cette méthode pour l'établissement d'arbres phylogénétiques. Ces travaux, confirmés par des études ultérieures, permirent en outre de mettre en évidence que les phytoplasmes seraient plus proches phylogénétiquement des Acholeplasma (mollicutes saprophytes) et des Anaeroplasma (mollicutes anaérobies) que des mycoplasmes animaux et des spiroplasmes. Tous possèdent Bacillus subtilis comme ancêtre commun (fig 1).

Ultérieurement, les résultats obtenus à la suite du séquençage de l'espaceur chez de nombreux phytoplasmes ont permis de confirmer et de préciser la position phylogénétique précédemment établie (Smart et al, 1994). Les phytoplasmes possèdent tous une seule copie du gène tRNA lle (isoleucine). Les mycoplasmes animaux en sont dépourvus et l'on observe une diversité des tRNA chez les spiroplasmes et les bactéries. Cette diversité se manifeste lorsque I'on amplifie l'espaceur. On obtient en effet un seul produit d'amplification dans le cas des phytoplasmes et des mycoplasmes, ce produit étant différent dans les 2 cas. En revanche, on observe, chez les bactéries, les acholéplasmes et les spiroplasmes, plusieurs produits d'amplification car 2 ou 3 espaceurs différents sont observés suivant les cas. Les espaceurs d'Escherichia coli, de Bacillus subtilis, d'Acholeplasma laidlawii, de phytoplasmes et de mycoplasmes sont représentés sur la figure 2. E coli possède 2 types d'opérons ribosomiques, I'un contenant les gènes tRNA isoleucine et tRNA alanine et l'autre le gène tRNA glutamine. Dans le cas de $B$ subtilis et $A$ laidlawii, le second opéron ne contient pas de gène tRNA. Lors de l'utilisation de l'espaceur pour l'établissement des arbres phylogénétiques par la méthode de parcimonie, les séquences les plus réduites de l'espaceur sont seules prises en compte.

En comparant les séquences de l'espaceur de phytoplasmes, spiroplasmes, acholéplasmes, mycoplasmes animaux par la méthode de PAUP, un arbre phylogénétique a pu être obtenu (fig 3 ) (Smart et al, 1994). Cet arbre apparaît en conformité avec les résultats précédents provenant de l'étude des séquences de la région codante du $16 S$ (fig 1). Les phytoplasmes occupent une position unique au sein des bactéries et sont plus proches phylogénétiquement des Acholeplasma que des mycoplasmes animaux et des spiroplasmes. 


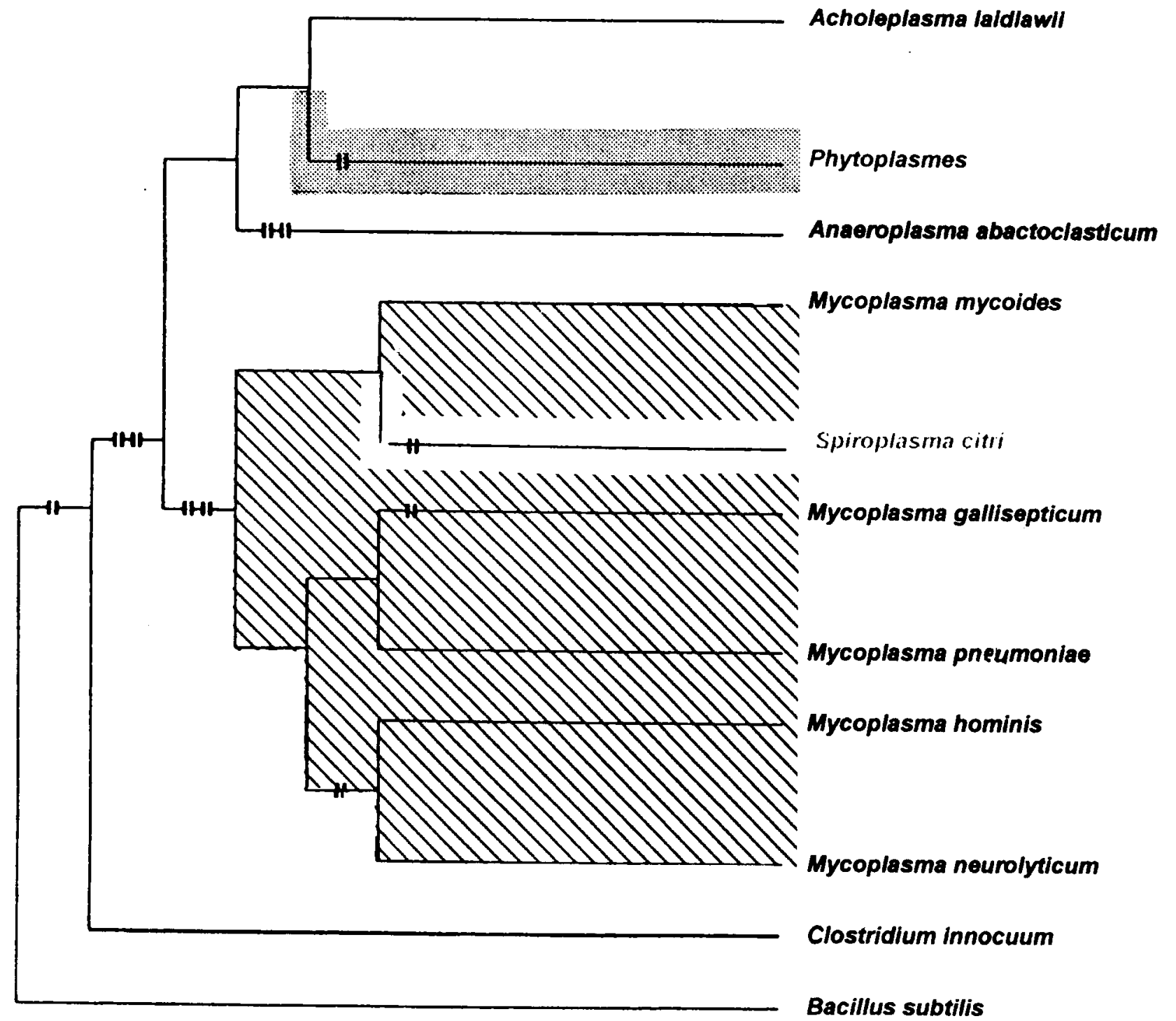

Fig 1. Arbre phylogénétique des phytoplasmes au sein des bactéries, établi par la méthode de parcimonie appliquée aux séquences de la fraction 16S de l'ADN ribosomique. (Résultats présentés au Comité de taxonomie des mollicutes de l'International Organization for Mycoplasmology.) Phytoplasmes (trame grisée) ; mycoplasmes animaux (trame hachurée).

\section{TENTATIVES DE CLASSIFICATION DE DIFFÉRENTES MALADIES LIÉES À LA PRÉSENCE DE PHYTOPLASMES}

\section{Utilisation du polymorphisme obtenu au niveau des profils électrophorétiques d'une fraction amplifiée de l'ADN ribosomique}

Les premières tentatives de classification des phytoplasmes résultent des travaux de l'équipe allemande de Dossenheim (Ahrens et Seemüller, 1992) qui utilisèrent des amorces universelles de phytoplasmes situées dans la région $16 \mathrm{~S}$ de I'ADN ribosomique pour amplifier un fragment de cet ADN (fig 4). Après digestion par des enzymes de restriction, ils comparèrent les différents pro- fils électrophorétiques observés lors de l'étude de 17 maladies (fig 5). L'étude du polymorphisme et l'établissement de cartes génétiques à partir de ces électrophorégrammes permirent de mettre en évidence la présence de 4 groupes chez les phytoplasmes.

Cette méthodologie fut utilisée pour relier le balai de sorcière du peuplier (PWB) au groupe «1" (Maurer et al, 1994), la phyllodie de la féverole existant au Soudan (FBP) au groupe «3», en particulier au balai de sorcière du chanvre du Bengale (SUNHwb) fréquemment observé en pays tropicaux (Saeed et Cousin, 1995), et la flavescence dorée de la vigne (FD) au groupe "4" auquel appartient également la jaunisse de l'orme (EYK).

L'utilisation de la PCR suivie d'une RFLP est la seule méthode de caractérisation possible 


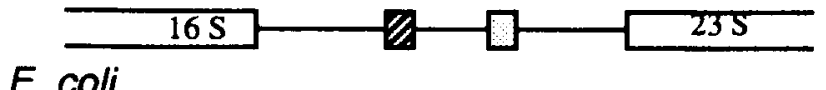

E. coli

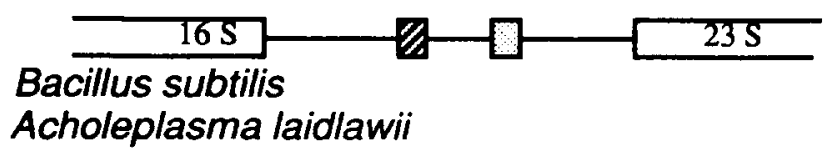

Phytoplasmes

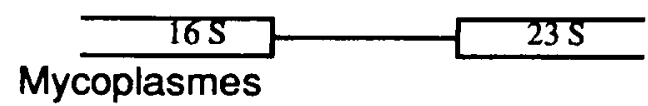

\section{t RNA isoleucine \\ $\square$ t RNA alanine \\ t RNA glutamine}

lorsque l'on ne dispose pas des séquences de la fraction 165 et de l'espaceur intergénique 16S$23 S$.

\section{Utilisation des séquences de la fraction $16 S$ et de l'espaceur}

Des arbres phylogénétiques ont été établis en appliquant la méthode de PAUP aux séquences de la fraction $16 S$ puis de l'espaceur.

Seemüller et al (1994), en comparant les séquences de la fraction $16 S$ de l'ADN ribosomique de 21 maladies à phytoplasmes sont parvenus à définir 5 groupes présentant une divergence des séquences non conservées (fig 6).

Ultérieurement le séquençage de l'espaceur devait permettre à son tour d'établir la phylogénie de ces maladies et de constater une grande homologie entre les résultats obtenus par l'étude des séquences de la fraction 165 et de l'espaceur.

Bien que quelques divergences subsistent entre les premiers résultats obtenus par l'observation du polymorphisme des profils électrophorétiques des fragments amplifiés, puis digérés par les enzymes de restriction, et ceux résultant de l'étude des séquences de l'ADN ribosomique, les homologies apparaissent nettement. Ainsi les groupes « 1 » et « 2 » contiennent dans tous les ou

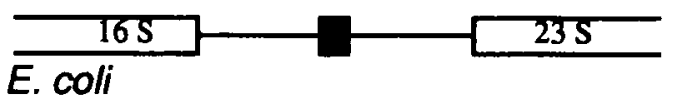

ou

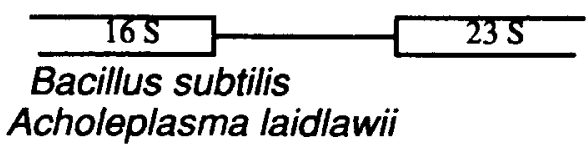

Fig 2. Différents espaceurs intergéniques 16S-23S présents chez Escherichia coli, Bacillus subtilis, Acholeplasma lailawii, phytoplasmes et mycoplasmes. (Résultats présentés au Comité de taxonomie des mollicutes de l'IOM.)

cas le stolbur (STOL), les aster yellows (MLO1, OAY, SAY, AAY, AV 2192) et la prolifération du pommier (AT). Le balai de sorcière de l'orme (ULW) constitue un groupe très éloigné génétiquement du premier groupe. Des convergences de plus en plus étroites sont attendues de l'utilisation, pour l'étude du polymorphisme des profils électrophorétiques, des nouvelles amorces universelles de phytoplasmes qui permettent l'amplification de la totalité de la fraction $16 \mathrm{~S}$ et de l'espaceur intergénique 16S-23S de I'ADN ribosomique.

\section{MÉTHODES DE DIAGNOSTIC}

Plusieurs méthodes peuvent être utilisées suivant les finalités recherchées, finalités qui dépendent de l'importance relative de la sensibilité et de la spécificité requises ainsi que des méthodologies disponibles.

\section{Cas d'un premier inventaire}

Dans le cas d'un premier inventaire des maladies à phytoplasmes dans une région donnée, la spécificité n'est pas le critère recherché. Le choix des méthodes sera alors dicté par la sensibilité requise liée au matériel végétal herbacé ou ligneux et par les méthodologies disponibles. 


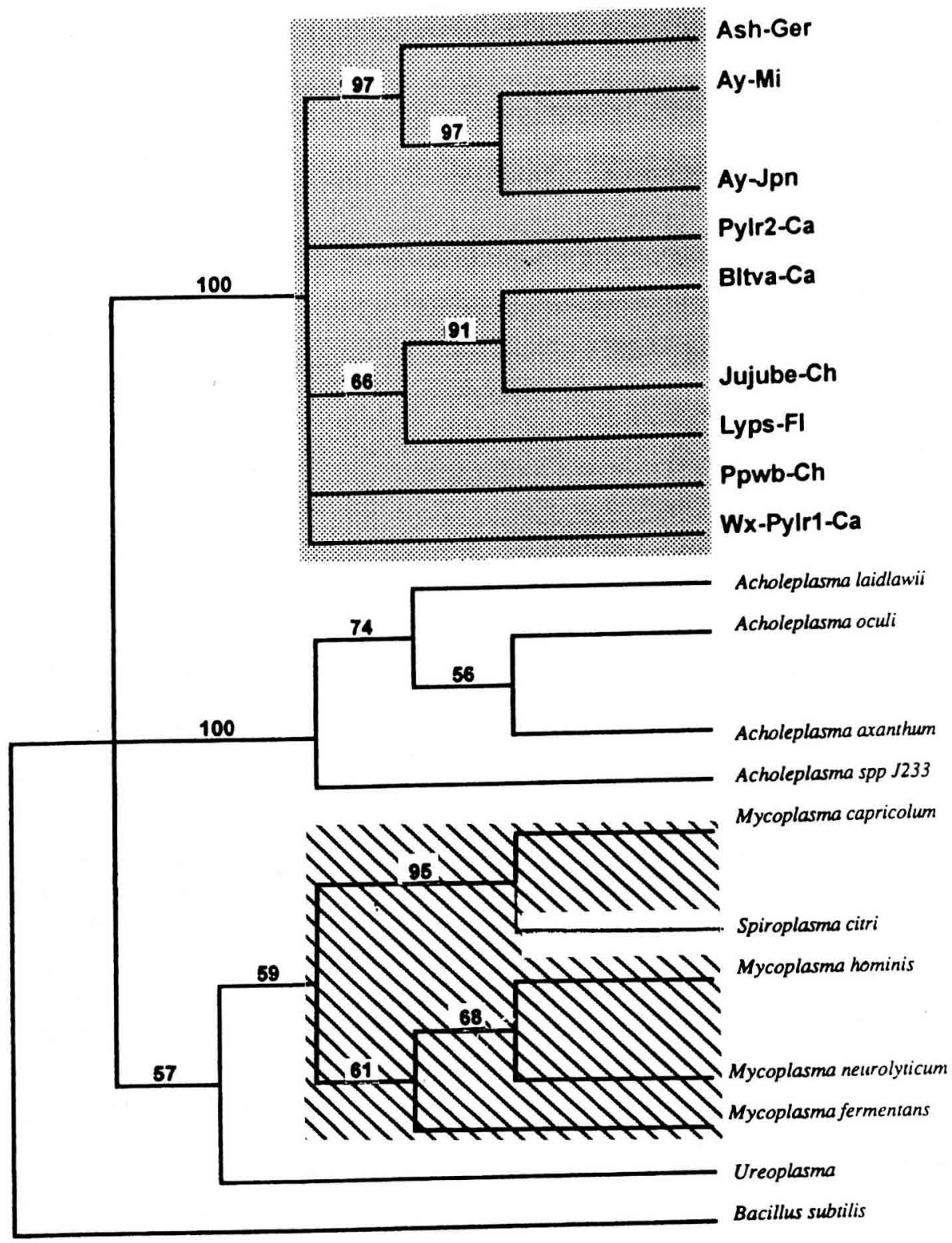

Fig 3. Arbre phylogénétique des phytoplasmes au sein des bactéries, établi par la méthode PAUP (Phylogenetic analysis using parsimony) appliquée aux séquences de l'espaceur intergénique 16S-23S de l'ADN ribosomique (Smart et al, 1994). Les chiffres indiqués sur l'arbre phylogénétique représentent en pourcentage les résultats statistiques de chaque embranchement. Phytoplasmes (trame grisée) ; mycoplasmes animaux (trame hachurée). Phytoplasmes : Ash-Ger, Ay-Mi, Ay-Jpn, Pylr2-Ca, Bltva, Jujube-ch, Lyps-FL, Ppwb-Ch, WX, Pylr1-Ca ; Acholeplasmes: Acholeplama laidlawii, A oculi, A axanthum et A sp J233 ; Spiroplasme : Spiroplasma citri; Mycoplasmes animaux : Mycoplasma capricolum, $M$ Hominis, $M$ neurolyticum, $M$ fermentans, Ureoplasma. Phytoplasmes, acholeplasmes, mycoplasmes animaux et spiroplasmes dérivent de Bacillus subtilis.

\section{Microscopie de fluorescence}

Dans un laboratoire de campagne, les méthodes faisant appel à la détection in situ en microscopie de fluorescence conservent toute leur valeur. On recommandera toujours l'observation parallèle de sections en l'absence de tout fluorochrome (autofluorescence) et en présence d'un fluorochrome caractéristique de I'ADN. L'autofluorescence permet de localiser les zones altérées des tissus de la plante. Une altération de la zone libérienne est un premier indice qui incite à poursuivre plus avant le diagnostic. La fluorescence primaire est particulièrement intense lorsque les réactions de la paroi libérienne sont importantes et que les phytoplasmes ont évolué vers des formes dégénérées. En revanche, elle peut passer inaperçue si les tissus de la plante sont peu altérés et si les phytoplasmes sont intacts. L'utilisation d'un fluorochrome spécifique de I'ADN, le réactif de 


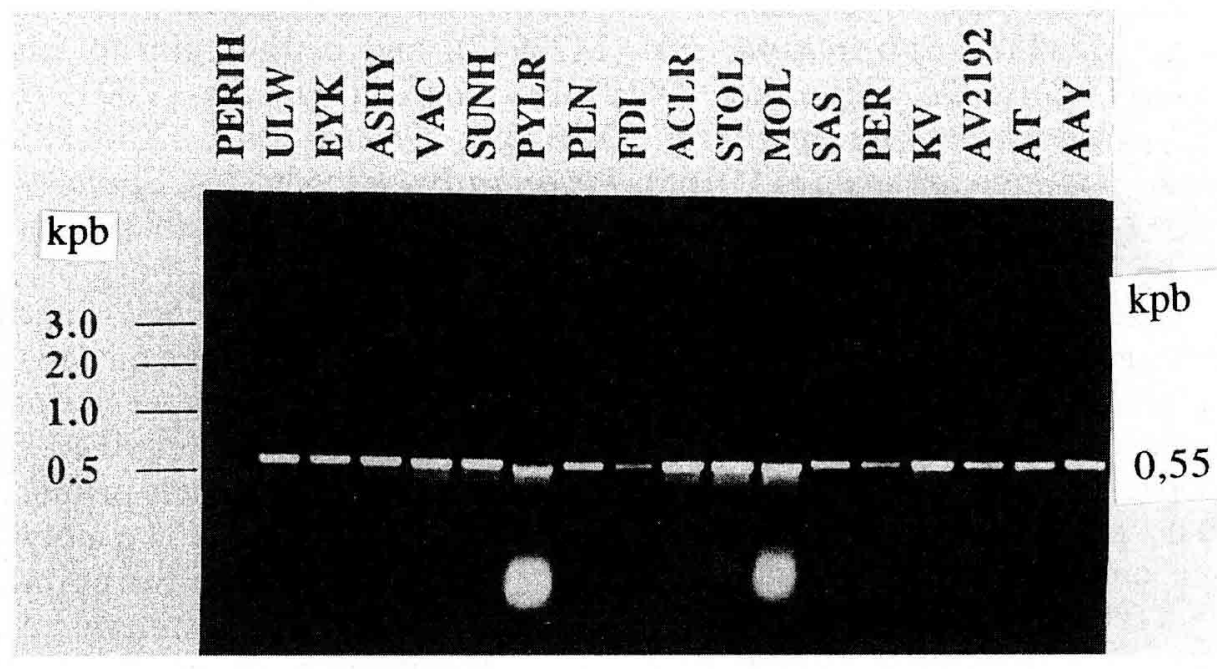

Fig 4. PCR utilisant des amorces universelles de phytoplasmes. Les 2 amorces universelles utilisées, $U 1$ et $U 4$, amplifient une fraction de 540 à 560 paires de bases du fragment 16S de I'ADN ribosomique. PERH (Healthy periwinkle ou Catharanthus roseus sain): pas d'amplification ; 17 ADN ribosomiques de phytoplasmes ont été amplifiés : ULW, EYK, ASHY, VAC, SUNHwb, PYLR, PLN, FDI, ACLR, STOL, MOL, SAS, PER, KV, AV2192, AT, AAY. (Les 2 taches blanches figurant sous les profils PYLR et MOL correspondent à la présence d'ARN.)

Hoechst (bisbenzimide), est indispensable à la détection des micro-organismes du phloème (Sharma et al, 1986) (fig 7), mais ne permet pas de distinguer les phytoplasmes des bactéries "fastidious" du phloème et des spiroplasmes.

\section{Microscopie électronique par transmission}

Une étude en microscopie électronique par transmission (MET) est conseillée dans les cas où un laboratoire spécialisé peut être consulté. II

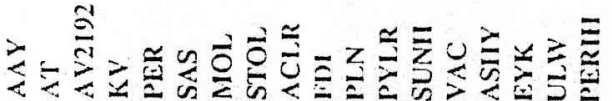
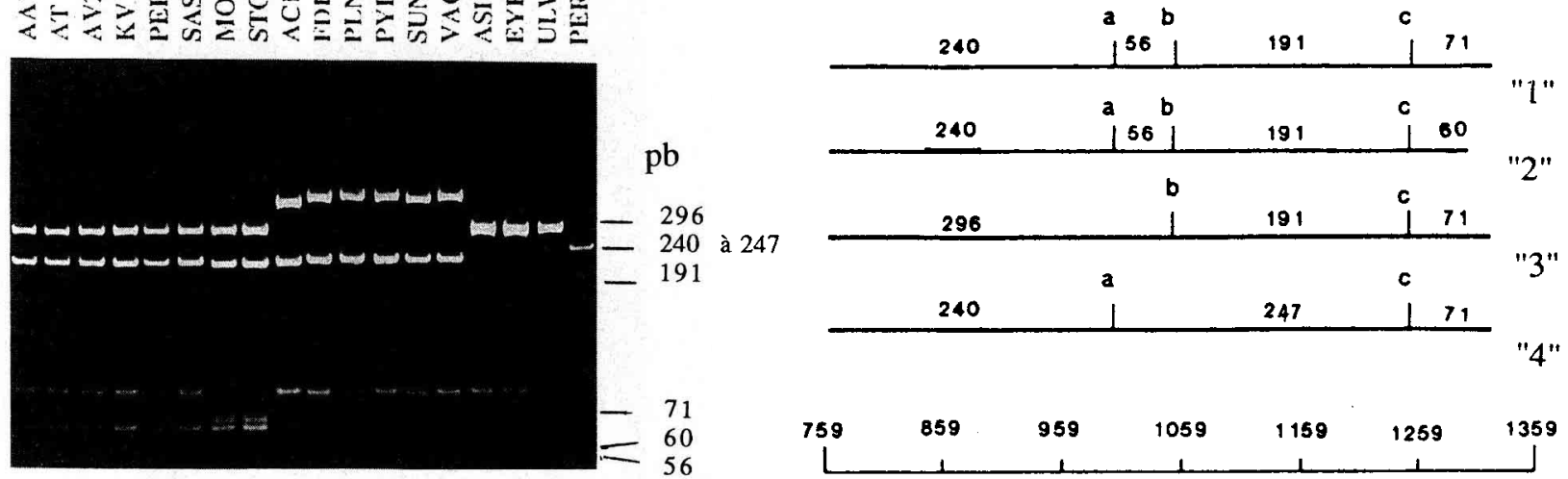

Fraction de 540 à 560 paires de bases de l'ADN ribosomique amplifiée par des amorces universelles de phytoplasmes.

Fig 5. Polymorphisme résultant de l'étude des profils électrophorétiques des produits de la digestion par Alu1 du fragment de 540 à $560 \mathrm{pb}$ de la fraction $16 S$ de I'ADN ribosomique amplifiée par PCR (Ahrens et Seemüller, 1992). À gauche, électrophorégramme. Les 17 maladies étudiées se répartissent dans les groupes suivants : groupe «1": AAY, AT, AV2192, KV, PER, SAS ; groupe «2" : MOL, STOL ; groupe «3»: ACLR, FDI, PLN, PYLR, SUNH, VAC ; groupe «4»: ASHY, EYK, ULW ; témoin : PER H (Healthy periwinkle ou Catharanthus roseus sain). Bande de très faible intensité observée chez la plante saine. À droite, cartes génétiques des fragments amplifiés, établies à partir de l'électrophorégramme. La position des bandes, visible de façon approximative sur l'électrophorégramme, est connue avec précision par les sites de coupure de l'enzyme Alu1. Ils se situent entre les bases $C$ et $G$ des séquences $5^{\prime}$ AG/CT 3' ou 3'TC/GA 5'. Groupes «1" et "2" : pratiquement identiques sur l'électrophorégramme, possédant en commun les 3 sites de coupures a, b, c (fragments de 56; 191 et $240 \mathrm{pb}$ dans les 2 cas). Le groupe «2" ne se distingue du groupe "1" que par un fragment plus court de l'extrémité 3 ' lié à la présence de séquences différentes à ce niveau : $71 \mathrm{pb}$ (groupe «1») et $60 \mathrm{pb}$ (groupe «2»). Groupe «3»: 2 sites de coupure en b et c (fragments de 71, 191 et $296 \mathrm{pb}$ ). Groupe «4»:2 sites de coupure a et c (fragments de 71 $\mathrm{pb}$ et bande relativement large correspondant à 2 bandes de 240 et 247 pb qu'il n'est pas possible de distinguer). 
conviendra de procéder successivement à des coupes longitudinales mettant en évidence le passage des phytoplasmes au travers des parois des tubes criblés du phloème (fig 8). Ces coupes ultra-fines seront observées à de forts grossissements atteignant 100000 afin de s'assurer de l'absence de paroi (fig 9) et ainsi distinguer les phytoplasmes des bactéries du phloème. À des grossissements inférieurs, des risques de confusion existent car la paroi de ces bactéries est souvent difficile à observer. II conviendra aussi de réaliser des coupes semi-fines, d'épaisseur comprise entre $400 \mathrm{~nm}$ et 1 micron, afin d'obtenir une vision tridimensionnelle (fig 10) indispensable pour conclure à l'absence de formes spiralées caractéristiques des spiroplasmes (Cousin et Sharma, 1986).
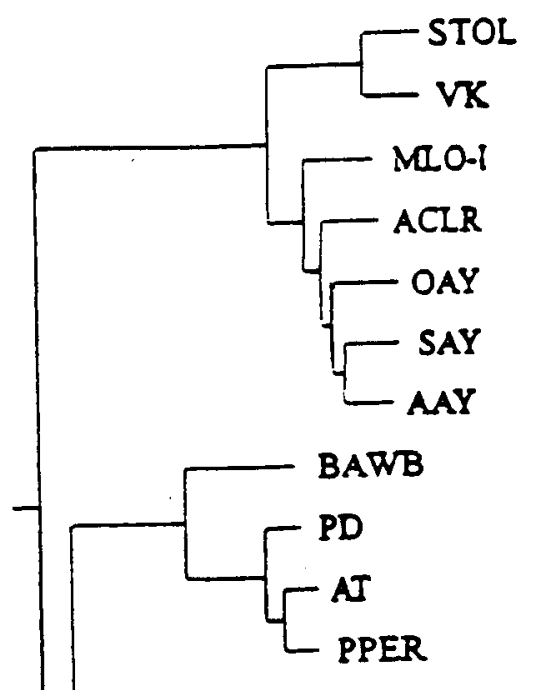

\section{SLNHP}

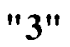

MLOII

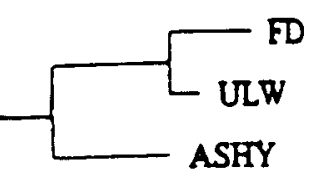

\section{$5 \%$}

Fig 6. Arbre phylogénétique établi à partir de 21 phytoplasmes par la méthode PAUP appliquée aux séquences de la fraction $16 S$ de l'ADN ribosomique (Seemüller et al, 1994). La barre de référence indique une distance d'évolution de $5 \%$. Les 21 maladies étudiées sont ici réparties en 5 groupes : groupe «1»: STOL, VK, MLOI, ACLR, OAY, SAY, AAY; groupe «2»: BAWB, PD, AT, PPER ; groupe «3»: SUNH «5»: FD, ULW et ASHY.
Dans le cas de l'inventaire de ces maladies sur des essences ligneuses, souvent peu concentrées en phytoplasmes, la sensibilité étant le principal critère recherché, les microscopies photonique en fluorescence et électronique peu-

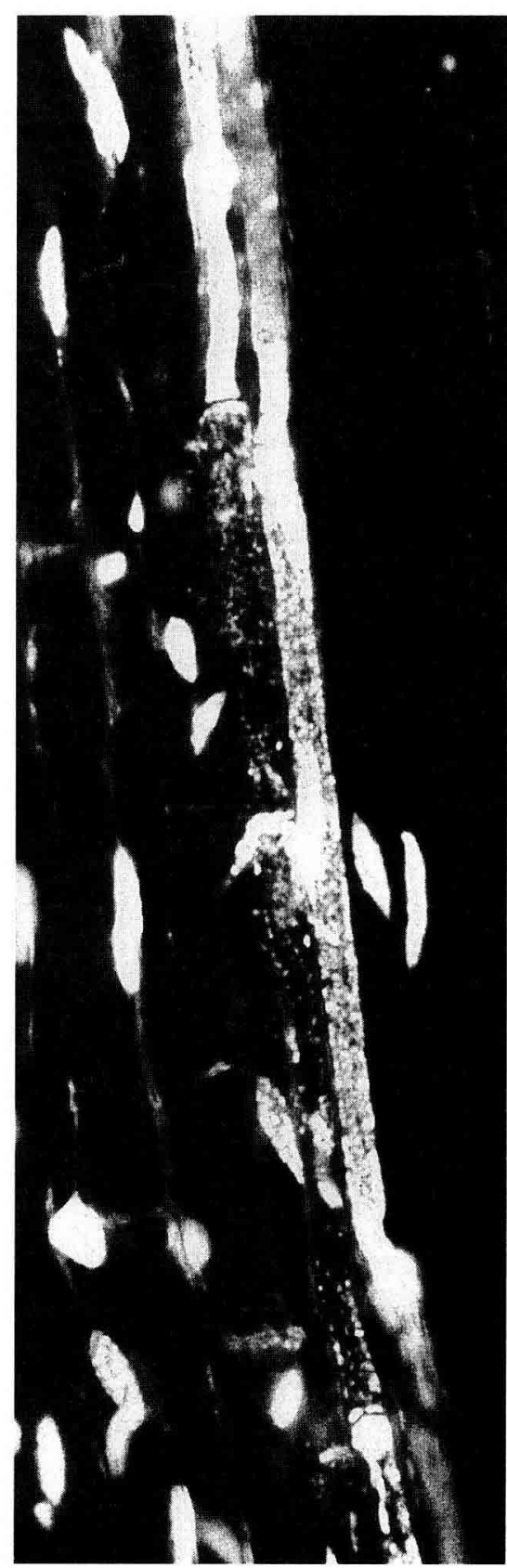

Fig 7. Utilisation d'un fluorochrome spécifique de I'ADN réactif de Hoechst (Bisbenzimide) sur coupe longitudinale de Catharanthus roseus atteint de phytoplasmose. Fluorescence de 2 tubes criblés infectés : l'intensité de la fluorescence varie suivant la partie du tube considérée. Une fluorescence homogène, indiquant une très forte concentration en phytoplasmes, est visible sur la partie du tube criblé située en haut et à gauche de la figure. Des phytoplasmes isolés plus ou moins nombreux sont visibles sur d'autres parties des tubes criblés. Présence de phytoplasmes concentrés au contact des parois criblées des tubes, parois elles-mêmes dépourvues de fluorescence. Noyaux des cellules de la plante également fluorescents mais nettement distincts des phytoplasmes. 


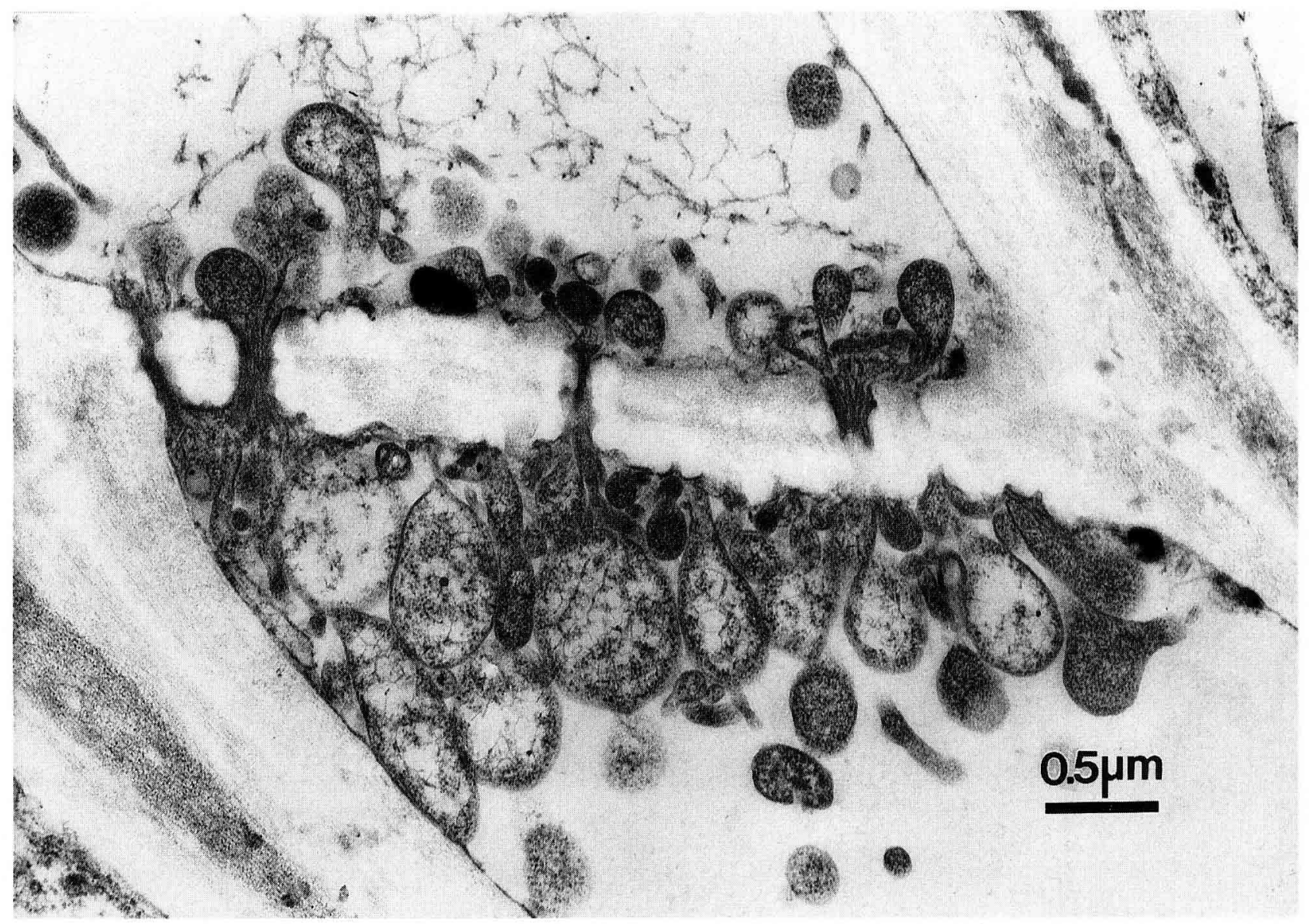

Fig 8. Phytoplasmes franchissant la paroi d'un tube criblé du phloème. (Grossissement : barre indiquant $0,5 \mu \mathrm{m}$.)

vent se révéler insuffisantes. Le diagnostic s'avère d'autant plus difficile que les symptômes s'intensifient, entraînant souvent une dégénérescence accrue des tubes criblés qui rend la détection impossible.

\section{PCR (Polymerase chain reaction) utilisant des amorces ribosomiques universelles de phytoplasmes}

La PCR utilisant des amorces ribosomiques universelles s'est révélée une méthode particulièrement intéressante dans le cas des espèces ligneuses, permettant la détection de la maladie avant même l'apparition des premiers symptômes. L'ADN ribosomique, en particulier la fraction 16S, est bien conservé chez les phytoplasmes et l'on dispose d'amorces universelles capables d'amplifier sans distinction tous les phytoplasmes. La bande amplifiée correspond à la taille du fragment d'ADN situé entre les amorces. La PCR avec amorces universelles constitue donc une première approche pour établir l'inventaire de maladies à phytoplasmes dans une région donnée.
Elle peut être, aussi, la première étape de leur caractérisation. On procèdera alors à une digestion des fragments amplifiés par des enzymes de restriction et l'on observera en électrophorèse, sur un gel de metaphor agarose ou de polyacrylamide, le polymorphisme des fragments amplifiés et digérés si les maladies étudiées appartiennent à des groupes différents.

\section{Cas d'études épidémiologiques}

Lors d'études épidémiologiques faisant intervenir la recherche des vecteurs et des plantes réservoirs de la maladie, la spécificité est le principal critère recherché. Plusieurs méthodes peuvent être envisagées en particulier la sérologie et la PCR utilisant des amorces spécifiques.

\section{Sérologie}

La sérologie constitue l'une des méthodes les plus spécifiques actuellement disponibles. Elle nécessite, suivant les cas, la préparation d'anti- 


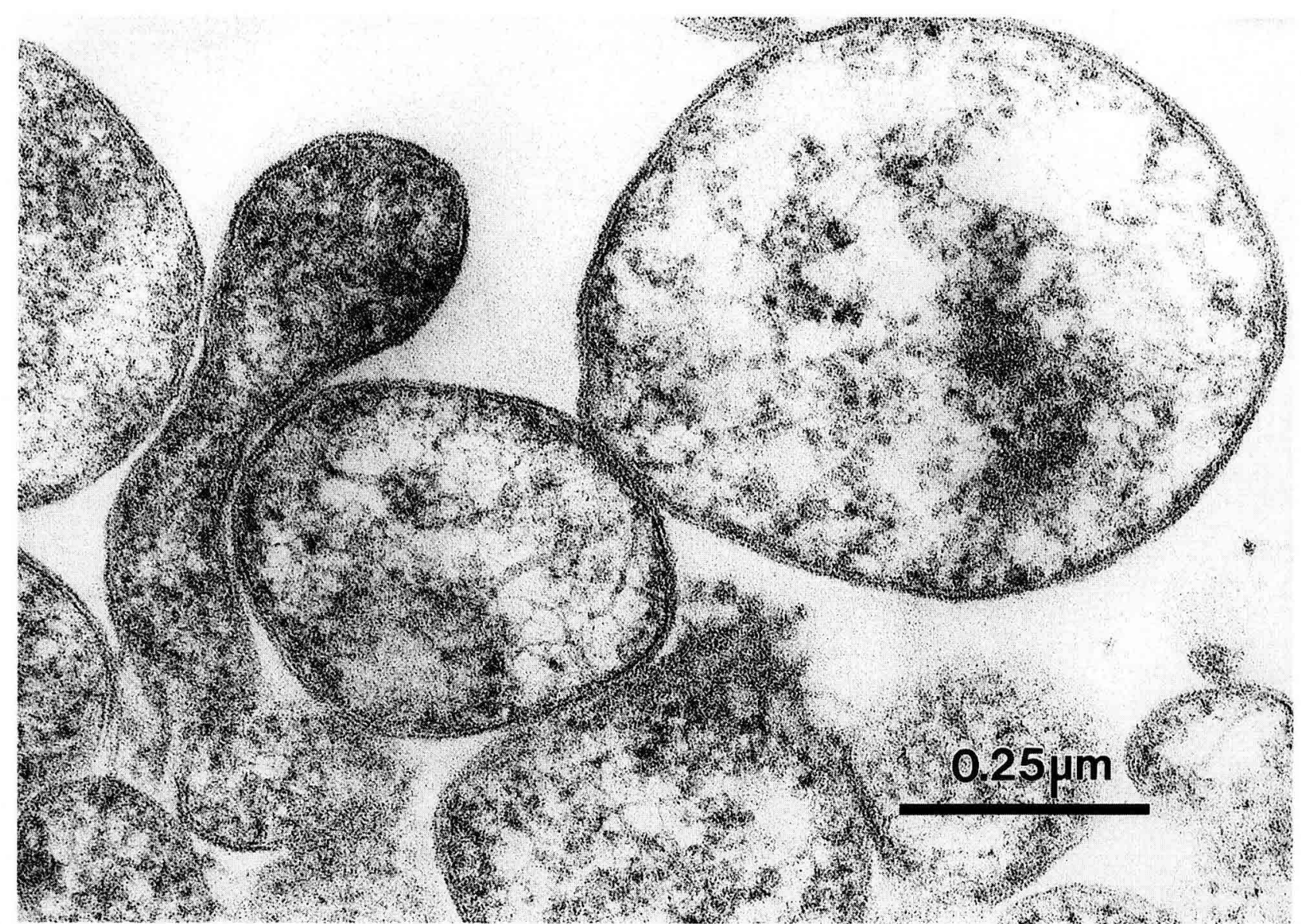

Fig 9. Ultrastructure de la membrane des phytoplasmes. (Grossissement : barre indiquant $0,25 \mu \mathrm{m}$.) Coupe ultrafine observée à un fort grossissement du microscope électronique (MET) permettant de s'assurer de l'absence de paroi et d'éviter la confusion avec les bactéries "fastidious" du phloème.

sérums poly ou monoclonaux. L'étape la plus critique pour leur préparation consiste à obtenir un extrait purifié des antigènes de plantes infectées. Pour cela on procède à un premier épuisement de cet extrait brut par un antisérum de plante saine. Lors de l'obtention d'un antisérum polyclonal, les IgG dirigées contre la plante malade seront à leur tour épuisées par une préparation purifiée de plante saine. Les antisérums peuvent être utilisés en immunofluorescence ou en ELISA. L'immunofluorescence indirecte, fréquemment pratiquée sur coupes avant la mise au point d'un test ELISA, permet d'éliminer les réactions non spécifiques liées à la présence éventuelle d'antigènes solubles en ELISA. Les variantes "sandwich" du test ELISA faisant intervenir en coating la fraction $F\left(a b^{\prime}\right) 2$ résultant de la digestion des IgG par la pepsine ou des anticorps de 2 espèces animales différentes (anticorps polyclonal de lapin et monoclonal de souris), contribuent grandement à améliorer la spécificité des tests.

Cette méthode a permis de distinguer la phyllodie de la féverole (FBP) existant au Soudan, du balai de sorcière du chanvre du Bengale (SUNHwb) présent en Thaillande (Saeed et al, 1994a) (fig 11). Ces 2 maladies tropicales appartiennent au même groupe « 3 " défini par Ahrens et Seemüller, 1992.

\section{PCR utilisant des amorces spécifiques d'une phytoplasmose donnée}

Si l'on veut accroître la sensibilité du diagnostic tout en conservant une bonne spécificité, l'utilisation en PCR d'amorces spécifiques est recherchée. Des séquences non conservées seront alors choisies au niveau de l'ADN génomique ou de I'ADN ribosomique (fraction $16 \mathrm{~S}$ ou espaceur intergénique). Selon les cas ces amorces pourront avoir une sensibilité très étroite (distinction entre isolats) ou plus large (distinction entre sous-groupes ou groupes).

\section{Utilisation de fragments spécifiques d'ADN génomique}

L'ADN génomique qui mesure de 600 à 1200 $\mathrm{kpb}$ chez les phytoplasmes est beaucoup moins 

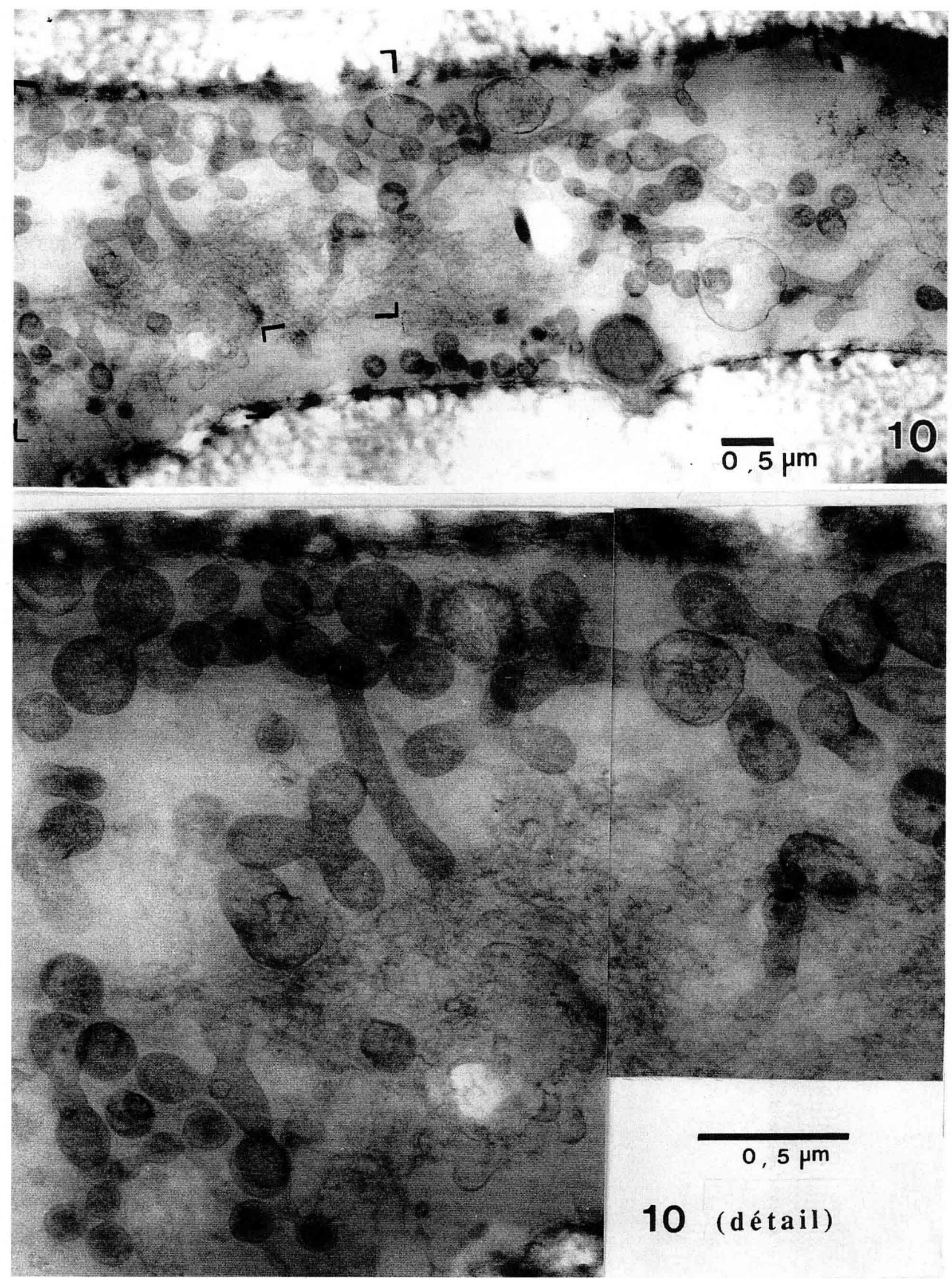

Fig 10. Vue tridimensionnelle de phytoplasmes en microscopie électronique par transmission (MET) permettant de s'assurer de l'absence de formes spiralées caractéristiques des spiroplasmes. Coupe semi-fine de $350 \mathrm{~nm}$ d'épaisseur. (Grossissement : barre indiquant $0,5 \mu \mathrm{m}$.) 
bien connu que I'ADN ribosomique. Ce dernier, de faible taille : $1,5 \mathrm{kpb}$ pour la fraction $16 \mathrm{~S}$ et $0,3 \mathrm{kpb}$ pour l'espaceur intergénique, a été séquencé dans de nombreux cas.

Les travaux antérieurs aux techniques PCR utilisaient des fragments de l'ADN génomique pour le clonage et la préparation de sondes (Kirkpatrick et al, 1987) marquées au ${ }^{32} \mathrm{P}$ ou à la digoxigénine. Ces sondes, par hybridation, permettaient une détection précise de l'ADN génomique étudié. Leur utilisation en «southern blot» reste une méthode de diagnostic adaptée à la routine permettant d'explorer la variabilité des séquences retenues parmi différents phytoplasmes ou isolats d'un même phytoplasme (Daire et al, 1992).

Actuellement, le séquençage des extrémités du fragment d'ADN cloné, choisi pour la préparation de la sonde génomique, conduit à l'obtention d'amorces spécifiques d'une maladie, qui sont choisies de telle sorte qu'elles ne présentent aucune homologie avec l'ADN de plante saine.
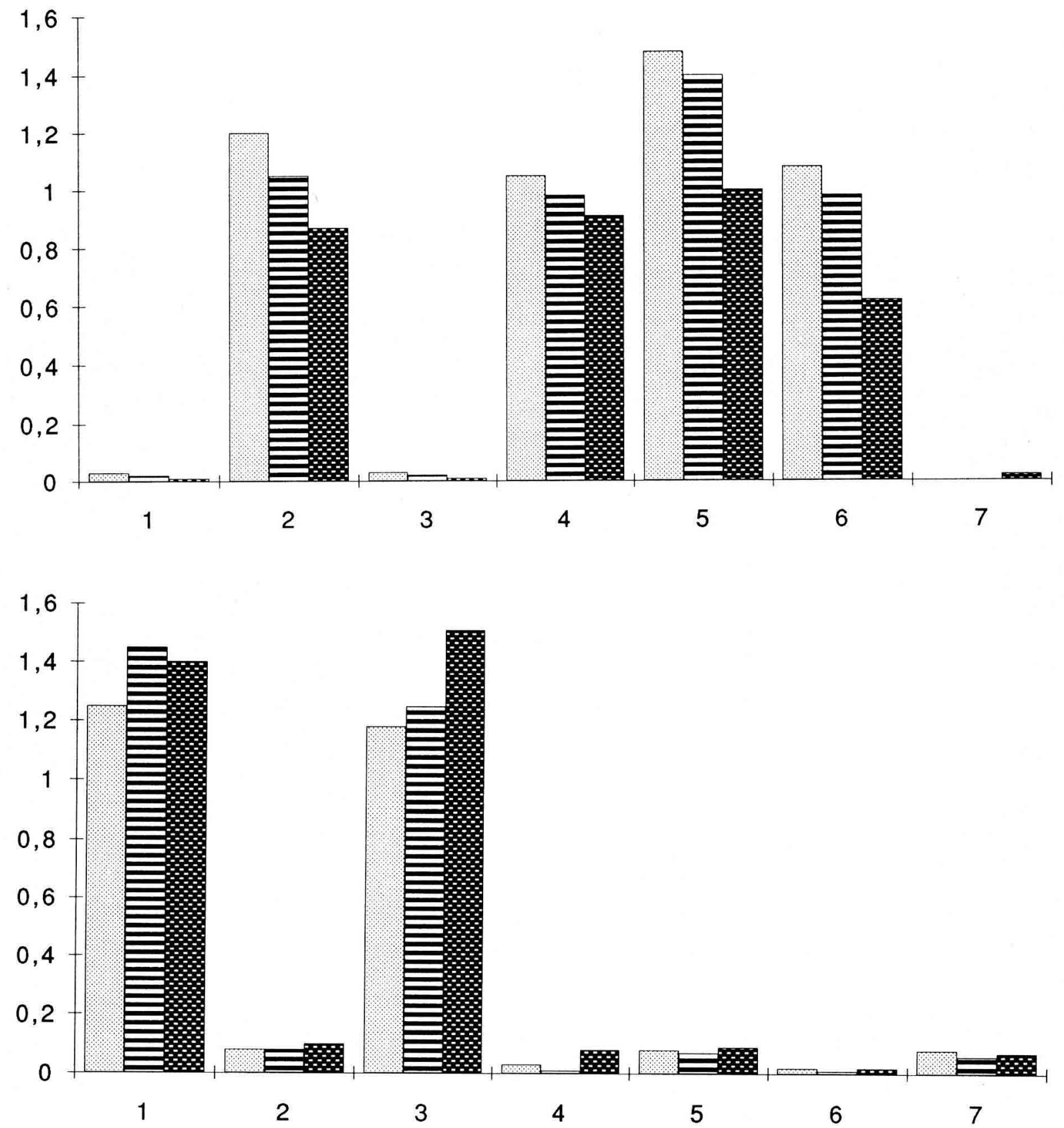

Fig 11. Test ELISA montrant l'absence de réactions immunologiques entre FBP et SUNH wb. (1) SUNH wb, (2) SUNH phyl, (3) SES, (4) SOY, (5) CSP, (6) FBP. (7) Catharanthus roseus sain. Partie supérieure de la figure : antisérum préparé contre FBP : positif : (2), (4), (5), (6) ; négatif : (1), (3), (7). Partie inférieure de la figure : antisérum préparé contre SUNH wb : positif : (1), (3) ; négatif : (2), (4), (5), (6), (7). Ordonnée : densité optique à $450 \mathrm{~nm}$. Abscisse : 3 dilutions successives $1 / 20$ (trame grisé clair), 1/60 (trame hachurée) et $1 / 180$ (trame foncée) pour chacune des maladies. 
Tableau II. Homologies existant entre FBP et SUNHwb d'une part (Saeed et al, 1994a, b; Saeed et Cousin, 1995), FD et EYK d'autre part (Daire et al, 1992), obtenues en utilisant successivement I'ADN ribosomique, I'ADN génomique et les antigènes.

\begin{tabular}{|c|c|c|c|}
\hline $\begin{array}{l}\text { Couples de maladies } \\
\text { à l'étude }\end{array}$ & $\begin{array}{c}\text { ADN ribosomique: } \\
P C R \text { (amorces universelles) } \\
\text { puis } R F L P\end{array}$ & $\begin{array}{c}\text { ADN génomique } \\
\text { Sondes } \\
\text { PCR (amorces spécifiques) }\end{array}$ & $\begin{array}{c}\text { Antigènes } \\
\text { ELISA } \\
\text { (antisérum polyclonal) }\end{array}$ \\
\hline $\begin{array}{l}\text { Phyllodie de la féverole } \\
\text { (FBP) et balai de sorcière } \\
\text { du chanvre du Bengale } \\
\text { (SUNH wb) }\end{array}$ & $\begin{array}{c}\text { Appartenance } \\
\text { au même groupe «3» }\end{array}$ & $\begin{array}{c}\text { (Fragment de } 1,35 \mathrm{kpb} \\
\text { d'ADN génomique utilisé) } \\
\text { Homologies nucléotidiques } \\
\text { partielles }\end{array}$ & $\begin{array}{l}\text { Absence de parenté } \\
\text { sérologique }\end{array}$ \\
\hline $\begin{array}{l}\text { Flavescence dorée de la vigne } \\
\text { (FD) et } \\
\text { jaunisse de l'orme (EYK) }\end{array}$ & $\begin{array}{c}\text { Appartenance } \\
\text { au même groupe «4» }\end{array}$ & $\begin{array}{l}\text { Homologies nucléotidiques } \\
\text { différentes suivant les fragments: } \\
\text { totales, partielles ou nulles }\end{array}$ & $\begin{array}{c}\text { Absence de parenté } \\
\text { sérologique }\end{array}$ \\
\hline
\end{tabular}

Dans le cas de la phyllodie de la féverole (FBP) originaire du Soudan, des amorces qui détectent spécifiquement la maladie étudiée sur différents hôtes (fort signal), permettent de déceler les homologies nucléotidiques partielles existant avec d'autres maladies (Saeed et al, 1994b) (fig 12). Ces résultats fournissent des informations complémentaires à celles enregistrées lors de l'étude de l'ADN ribosomique, qui révélaient seulement l'appartenance de ces maladies au groupe « 3 ", et lors des tests ELISA qui les distinguaient totalement.

L'ensemble des informations concernant les homologies existant entre 2 couples de maladies : phyllodie de la féverole (FBP) et balai de sorcière du chanvre du Bengale (SUNHwb) d'une part, flavescence dorée de la vigne (FD) et jaunisse de l'orme (EYK) d'autre part, révélées lors des études successives des ADN ribosomique, génomique et des antigènes sont consignées sur le tableau II. II montre que 2 couples de maladies appartenant au même groupe défini par l'ADN ribosomique et totalement distinctes lors des tests ELISA présentent, selon le fragment d'ADN génomique choisi pour la préparation des sondes ou des amorces spécifiques, des homologies nucléotidiques totales, partielles ou nulles.

La préparation d'amorces génomiques spécifiques requiert un travail considérable lié à l'obtention d'un ADN suffisamment purifié pour la préparation des sondes, et au clonage dans des plasmides.
Utilisation de fragments spécifiques, non conservés, de la fraction 165 et de l'espaceur 16S-23S de l'ADN ribosomique

À l'heure actuelle les travaux s'orientent vers la recherche de fragments non conservés à l'intérieur de la fraction $16 \mathrm{~S}$ et de l'espaceur 16S-23S de I'ADN ribosomique. La connaissance des séquences de ces fragments permet une détection spécifique de groupes ou de souches.

En ce qui concerne la fraction 16S, bien qu'elle soit constituée prioritairement d'ADN conservé, non spécifique d'une maladie, elle contient également des ADN non conservés, sièges de la spécificité et pouvant être utilisés pour la fabrication d'amorces spécifiques de différentes maladies.

Mais c'est au niveau de l'espaceur, au voisinage du gène tRNA isoleucine très conservé chez l'ensemble des phytoplasmes, que l'on découvre le maximum d'ADN non conservé, spécifique de plusieurs phytoplasmoses. Le séquençage de ces régions non conservées a permis l'obtention d'amorces très spécifiques de certaines maladies. On utilise alors, pour la PCR, des amorces "reverse ou aval" situées dans les fractions non conservées de l'espaceur et des amorces «forward ou amont" situées dans le segment $16 \mathrm{~S}$. La figure 13 montre la localisation des amorces "reverse ou aval» situées dans l'espaceur et spécifiques de plusieurs maladies: BLTVA, SAY, PYLT2, WX (Kirkpatrick et al, 1994). 

0 1 2
34
5
6
$\begin{array}{lll}8 & 9 & 10\end{array}$

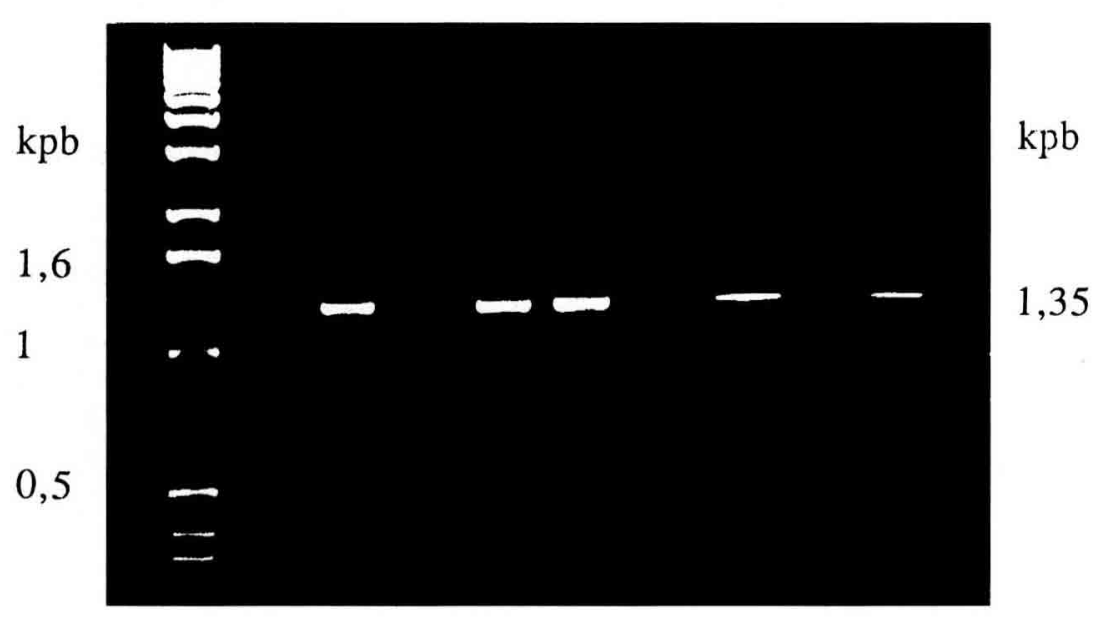

Fig 12. PCR utilisant des amorces spécifiques de FBP (Saeed et al, 1994b). (0) : marqueur de poids moléculaires, $1 \mathrm{~kb}$ DNA ladder. La taille de 3 fragments est indiquée en kilo paires de bases $(\mathrm{kpb})$ : $(0,5),(1)$ et $(1,6)$. (1) : Féverole saine. $(2)$ : FBP sur Catharanthus roseus, (3) : CRP, (4) : FBP sur Vicia faba, (5): CSP, (6): AY gl, (7) : SUNH wb, (8): YDL, (9) : TBB, (10) : CP. Les 2 amorces utilisées $E 1$ et $E 2$ amplifient spécifiquement une fraction de 1,35 kpb de l'ADN génomique. Fort signal : homologie nucléotidique complète (puits $2,4,5$ ). Absence de signal: pas d'homologie nucléotidique (puits $1,3,6,8,10$ ). Faible signal : homologie nucleotidique partielle (puits 7 et 9 ). FBP ne présente qu'une homologie nucléotidique partielle des séquences de I'ADN génomique avec SUNH wb et TBB.

\section{VECTION}

Les phytoplasmes sont transmis par des insectes homoptères auchénorrhynques, les cicadelles, dans la plupart des cas, à l'exception du dépérissement du poirier ou pear decline (PD), dont les vecteurs sont des psylles. Pour que la piqûre de l'insecte soit efficace, elle doit atteindre les tubes criblés. Une piqûre s'arrêtant en plein parenchyme reste inefficace, la transmission ne pouvant être assurée que par le contact des tissus conducteurs.

La période d'incubation correspond au laps de temps qui s'écoule entre la prise de nourriture sur une plante infectée et la transmission à une plante saine des phytoplasmes présents dans la salive de l'insecte. Les travaux concernant Euscelidius variegatus, vecteur expérimental de la flavescence dorée de la vigne (FD), effectués à l'aide d'anticorps polyclonaux en utilisant conjointement la technique d'immunomarquage à l'or colloïdal en microscopie électronique, l'amplification à l'argent en microscopie photonique et les tests ELISA (Lefol et al, 1994), ont permis de suivre avec une grande précision le processus d'infection et de multiplication des phytoplasmes chez l'insecte. Ils sont détectés, dès la première semaine après leur acquisition, dans le tube digestif. Ils atteignent l'hémolymphe où ils circulent sans multiplication la seconde semaine. Les glandes salivaires principales postérieures sont à leur tour infectées la cinquième semaine. Elles constituent un site très important de multiplication au niveau des acinus $3,4,5$ qui sont seuls infectés (fig 14), ce qui pose le problème de la nature des récepteurs.
Les premiers résultats obtenus, en utilisant la technique d'immunomarquage pratiquée à l'aide d'anticorps monoclonaux dirigés contre la flavescence dorée de la vigne (FD) sur des cryocoupes de cicadelles saines incubées avec un extrait enrichi du phytoplasme responsable de cette maladie, montrent qu'une interaction lectine-glycoprotéine serait impliquée dans les phénomènes de reconnaissance (Lefol et al, 1993).

Les phytoplasmes infectent ensuite les autres organes, corps gras et mycétome, mais les tubes de Malpighi et les organes génitaux ne sont jamais atteints, ce qui explique que les phytoplasmes ne puissent pas être transmis d'une génération à l'autre par l'intermédiaire des œufs. Ils peuvent, cependant, hiverner dans les larves ou les adultes et se révéler infectieux dès leur reprise d'activité au printemps.

Les phytoplasmes ne sont pas pathogènes pour les insectes vecteurs dont seules la longévité et la fécondité sont parfois réduites. Aucun phénomène cytopathologique tel que la présence de lésions cellulaires n'a été enregistré dans le cas de la flavescence dorée de la vigne (FD). Aussi l'appellation "phytoplasme» a été retenue bien qu'elle ne reflète pas leur multiplication à l'intérieur du vecteur.

En pays tropicaux, le grand nombre de cycles des vecteurs et des plantes réservoirs adventices, contribue à l'incidence désastreuse de ces maladies sur les cultures.

La connaissance des différents insectes vecteurs d'une maladie, de leur cycle et celle des plantes sur lesquelles ils se nourrissent constituent le fondement des méthodes de lutte indirectes jusqu'ici utilisées. 


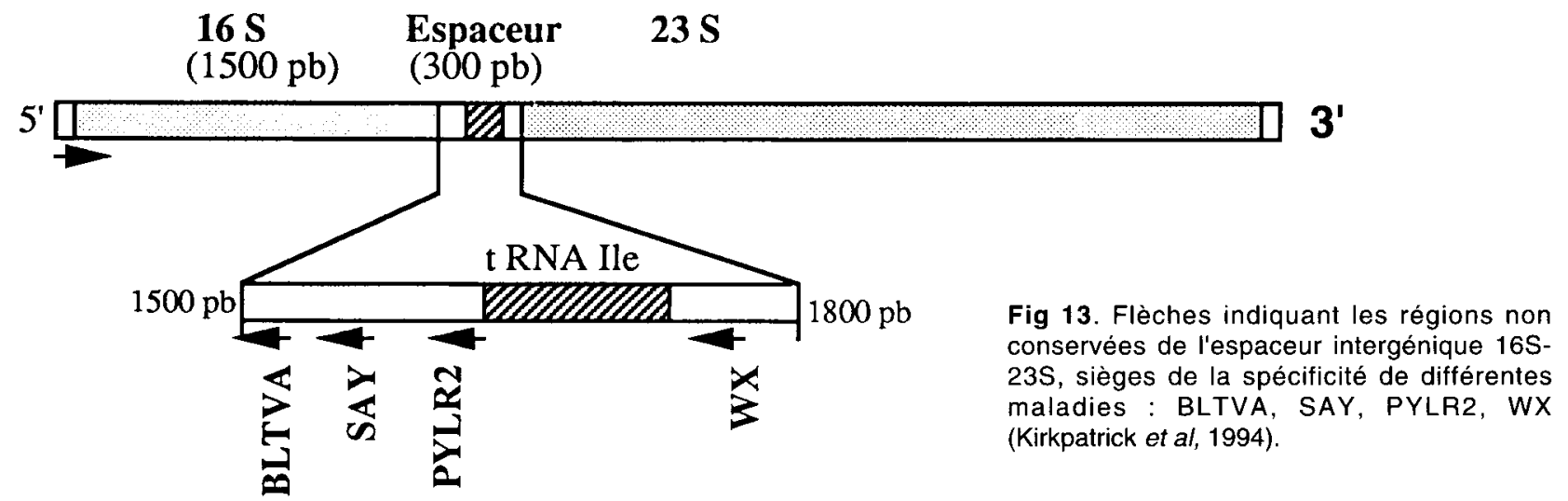

\section{MÉTHODES DE LUTTE}

\section{Amélioration de l'état sanitaire du matériel de base dans le cas d'espèces multipliées végétativement}

La création de pépinières avec certification sanitaire peut désormais être envisagée en utilisant les méthodes de diagnostic précédemment décrites. Un stock de pieds-mères sains pourrait être ainsi constitué dans le cas d'espèces mutipliées végétativement. La mise en place de ce matériel de base contrôlé contribuerait à l'amélioration de l'état sanitaire de la production des plants qui jusqu'ici s'effectue sans aucun contrôle sur certaines essences ligneuses tel le peuplier ou sur plantes horticoles vivaces tel l'hortensia. La matériel de base pourrait être, suivant les cas, issu de simple bouturage ou de culture in vitro.

La micropropagation peut en effet être utilisée à plusieurs fins. La teneur en phytoplasmes des explants peut être augmentée par la micropropagation, ce qui facilite le diagnostic. Cette méthode a été utilisée dans le cas de peuplier atteint de witches' broom (PWB) (Cousin et al, 1990). À l'inverse, dans un but d'épuration, des antibiotiques du groupe des tétracyclines ou divers constituants chimiques sont incorporés au milieu de culture constitué de substances défavorables à la multiplication des phytoplasmes. Ces antibiotiques autorisés en micropropagation sont interdits dans la nature en Europe. Ils ont cependant été utilisés en Amérique dans la lutte contre les maladies à phytoplasmes des arbres fruitiers telles que la jaunisse létale du palmier à huile ou lethal yellowing of coconut palm (LY), la maladie $X$ du pêcher (peach $X$ disease) et le sandal spike (SAS). Après la récolte, un trocard est enfoncé dans le tronc jusqu'aux tissus conducteurs et le liquide est injecté goutte à goutte. On réduit ainsi les pertes de récolte à venir tout en diminuant au maximum les risques pour l'environnement puisque le traitement intervient après la récolte, qu'il ne subsiste aucune trace d'antibiotique à la surface des arbres et que les doses utilisées sont très faibles. En Europe ces traitements sont cependant interdits en raison des risques encourus par l'éventuel transfert à d'autres microorganismes de la résistance aux antibiotiques par l'intermédiaire des plasmides.

La thermothérapie peut aussi être envisagée pour le traitement de jeunes plants de pépinière, peupliers en particulier (Van der Meer, 1980).

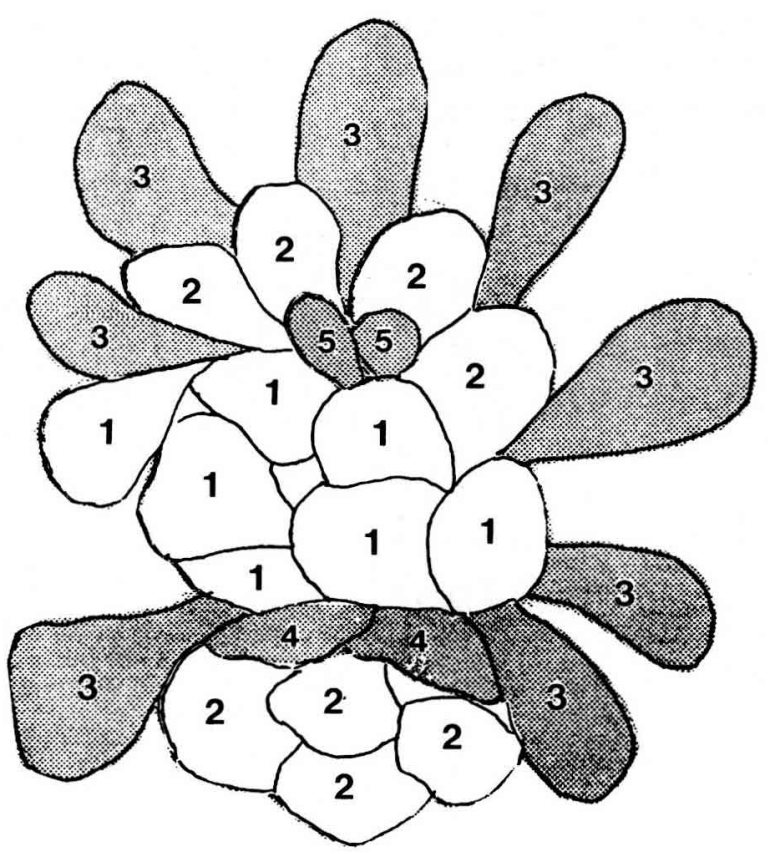

Fig 14. Localisation des phytoplasmes de FD dans les acinus des glandes salivaires infectées. (Lherminier, thèse de doctorat de l'université de Bourgogne. "Apport de la cytologie moléculaire à l'étude des relations hôtes-micro-organismes non cultivables : 'mycoplasma-like organisms' et champignons endomycorhizogènes"). Acinus $(1,2,3,4,5)$ d'une glande principale postérieure. Seuls les acinus 3,4 et 5 (trame foncée) sont colonisés par les phytoplasmes. 


\section{Maintien de l'état sanitaire des plantes}

Le traitement indirect par application d'insecticides demeure à l'heure actuelle la méthode la plus couramment utilisée pour lutter contre les phytoplasmes. La lutte peut être envisagée efficacement lorsqu'il n'existe qu'une seule espèce de cicadelles vectrices, qu'elle ne possède qu'une seule génération par an et qu'elle est inféodée à l'espèce étudiée (Schvester et al, 1962). La flavescence dorée de la vigne (FD) répond à ces 3 critères et la préconisation de traitements à date fixée a pu être mise au point à I'INRA de Dijon (Caudwell, 1990).

Dans le cas de la phyllodie du trèfle (CP), plusieurs cicadelles vectrices ont été identifiées: Euscelis incisus, $E$ lineolatus, $E$ variegatus et Aphrodes bicinctus. La découverte de leur cycle devait conditionner la lutte contre ces maladies (Cousin et al, 1965). E incisus possède plusieurs générations par an. Son mode d'hivernation est lié aux conditions climatiques. Dans l'ouest de la France où son étude a été entreprise pour enrayer la maladie qui interdisait toute récolte de graines dans les pépinières de trèfle blanc, $E$ incisus hiverne principalement aux derniers stades larvaires et accessoirement à l'état d'œufs (fig 15). Or, les larves infectées l'année précédente constituent des réservoirs importants de la maladie. En revanche, aucune transmission par les œufs n'a été enregistrée à ce jour. On conçoit donc l'importance de la génération de printemps issue de larves hivernantes et dont le réveil s'effectue dès le mois de mars. Ces insectes sont capables d'infecter aussitôt la plante si leur inoculation à partir de plantes malades a eu lieu l'année précédente. La «période d'incubation" dans l'insecte, qui peut atteindre jusqu'à 6 sem selon les conditions climatiques, est alors achevée. Les générations d'été issues d'œufs sont moins préjudiciables. Leur pouvoir infectieux n'intervient qu'après achèvement de la "période d'incubation" dans l'insecte. Elles sont issues à la fois des œufs d'hiver et des œufs pondus par la génération de printemps. À la fin de l'été apparaîtront les formes d'hivernation : larves et œufs. Les plants de trèfle inoculés à cette période de l'année par les cicadelles n'extérioriseront leurs symptômes que l'année suivante. Ils constitueront, avec les larves hivernantes, les principaux réservoirs de la maladie, alors que les trèfles inoculés au printemps se rétablissent ou meurent en cours de I'hiver. Une lutte contre l'insecte peut donc être programmée dès l'apparition de la première génération de printemps et à l'automne, donc en dehors des périodes de pollinisation par les abeilles. Le rôle des autres cicadelles vectrices de la phyllodie du trèfle (CP), hivernant exclusivement à l'état d'œufs, est apparu secondaire dans l'ouest de la France. La connaissance des cycles des différents vecteurs de la maladie a permis une lutte efficace. II convient, suivant les régions considérées, d'entreprendre une étude préalable des cycles des vecteurs qui varient en fonction des conditions climatiques.

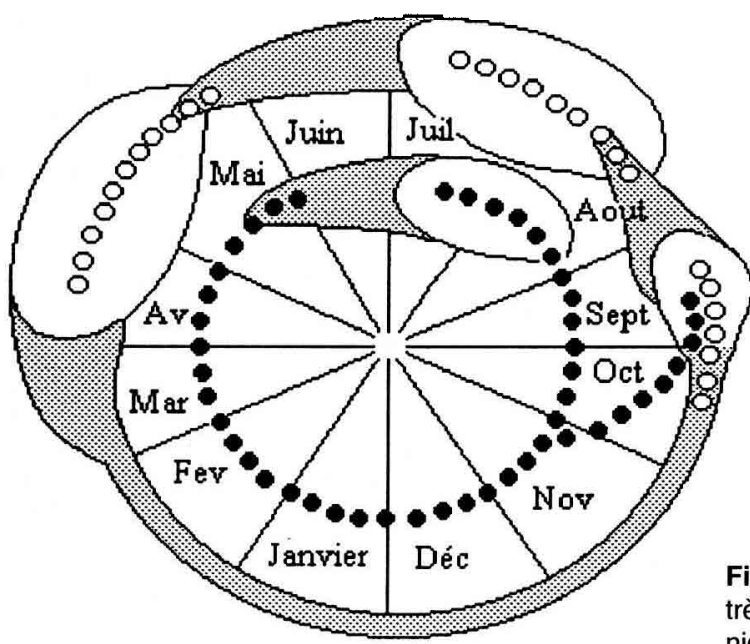

Fig 15. Cycle d'Euscelis incisus, vecteur de la phyllodie du trèfle $(C P)$, dans une zone de transition entre le climat océanique tempéré et le climat continental.
- $\bullet \bullet \bullet$ oeuf à diapause

00000 oeuf sans diapause
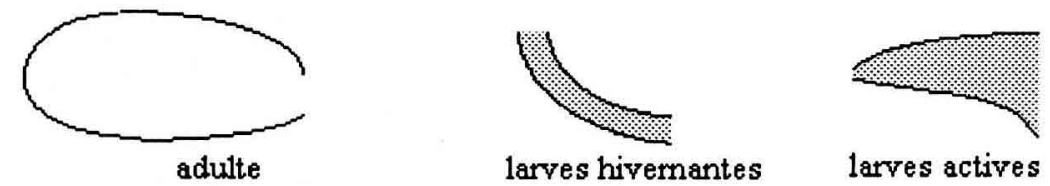

larves actives 
Dans les zones océaniques, la forme hivernante est essentiellement constituée de larves. Dans les zones de transition entre le climat océanique tempéré et le climat continental, ces modes d'hivernation ont une importance comparable. Dans les zones continentales, les insectes hivernent principalement à l'état d'œufs.

En l'absence du vecteur, on assiste à une évolution conduisant à la mort des plantes malades ou à leur guérison. Cette faculté de rétablissement peut être exploitée dans la mise au point d'une stratégie de lutte.

Cependant il existe des cas où les traitements insecticides sont inefficaces, par exemple lorsque les vecteurs effectuent la majorité de leurs cycles sur des espèces adventices situées à l'extérieur de la culture considérée.

De plus, dans certains cas, en zone urbaine ou périurbaine en particulier, les traitements insecticides ne peuvent être envisagés. On ne dispose alors que de pratiques culturales permettant de contenir la maladie. Ainsi l'élagage des branches situées à la base des peupliers, en entravant la migration des larves vers les parties supérieures de l'arbre, contribue à freiner l'extension de la maladie des balais de sorcière du peuplier (PWB). Ces méthodes palliatives sont insuffisantes pour une éradication complète.

La résistance génétique constitue toujours la méthode de choix pour lutter contre ces maladies. Quelques résultats intéressants ont été obtenus dans le cas de la jaunisse létale du palmier ou palm lethal yellowing (LY) (Mc Coy et al, 1983), de la maladie des petites feuilles de l'aubergine ou little leaf of brinjal (BLL) (Memane et Joi, 1987) et de la jaunisse de l'orme ou elm yellows (EYK) (Mittempergher et al, 1990). Malheureusement les résistance connues à l'heure actuelle sont encore peu nombreuses.

Les travaux réalisés en laboratoire pour l'obtention de plantes transgéniques résistantes aux insectes ouvrent de nouvelles perspectives. Deux stratégies peuvent être employées.

La première, largement développée, utilise la toxine produite par une bactérie: Bacillus thuringiensis (Peforoen, 1992). Cette bactérie entraîne chez l'insecte l'apparition d'une protéine cristalline qui, lorsqu'elle s'hydrolyse dans ses glandes salivaires, produit un fragment toxique. $B$ thuringiensis est bien connu comme biopesticide dans le cas de lépidoptères et de coléoptères.

La seconde, plus récente, fait appel aux gènes dérivés de plantes pour entraver le développement des insectes au moyen d'inhibiteurs d'en- zymes (Boulter, 1993). Récemment un gène codant pour une lectine a été exprimé dans le riz sous le contrôle d'un promoteur spécifique du phloème dans le but d'obtenir des plantes résistantes aux homoptères chez cette espèce (Tang et al, 1994).

À l'heure actuelle, la recherche de plantes possédant la résistance à l'insecte vecteur semble plus prometteuse pour le contrôle de ces maladies que celle de plantes résistant aux phytoplasmes eux-mêmes.

\section{RÉFÉRENCES}

Ahrens U, Seemüller E (1992) Detection of DNA of plant pathogenic mycoplasma-like organisms by a polymerase chain reaction that amplifies a sequence of the 16 S RNA gene. Phytopathology 82 , $8,828-832$

Boulter D (1993) Insect pest control by copying nature using genetically engineered crops. Phytochemistry 34.6, 1453-1466

Caudwell A (1990) Epidemiology and characterization of flavescence dorée (FD) and other grapevine yellows. agronomie 3, 103-111

Cousin MT, Moreau JP, Van Loon LC (1965) Les maladies du trèfle transmises par cicadelles en France. Ann Epiphyties 16, 1, 137-149

Cousin MT, Darpoux H, Faivre-Amiot A, Staron (1970) Sur la présence de micro-organismes de type mycoplasme dans le parenchyme cortical de féveroles présentant des symptômes de virescence. $C$ R Acad Sci 271, 1182-1184

Cousin MT, Sharma AK (1986) Association of mycoplasma-like organisms (MLOs) with mild type of Hydrangea virescence: a study with 60-1 $000 \mathrm{~nm}$ thick sections. J Phytopathol 115, 274-282

Cousin MT, Sharma AK, Rousseau J, Poitevin JP, Savouré A (1986) Hydrangea virescence. I. Description of the disease and its transmission to differential host plant Catharanthus roseus by Cuscuta subinclusa. agronomie 6, 3, 249-254

Cousin MT, Roux J, Millet N, Michel MF (1990) Maintenance of MLOs (mycoplasma-like-organisms) on Populus alba micropropagation. J Phytopathol 130, 17-23

Daire X, Boudon-Padieu E, Bervillé A, Schneider B, Caudwell A (1992) Cloned DNA probes for the detection of grapevine flavescence dorée mycoplasma-like organism (MLO). Ann Appl Biol 121, 95-103

Deng S, Hiruki C (1991) Amplification of 16S rRNA genes from culturable and nonculture mollicutes. $J$ Microb Meth 14, 53-61

Kirkpatrick B, Stenger DC, Morris TJ, Purcell AH (1987) Cloning and detection of DNA from a nonculturable plant pathogenic mycoplasma-like organism. Science 238, 197-200 
Kirkpatrick B, Smart C, Blomquist C et al (1994) Identification of MLO-specific PCR primers obtained from 16S/23S rRNA spacer sequences. 10th Intern Congr Intern Organization for Mycoplasmology (IOM), Bordeaux, France, July 19-26, 261-262

Lefol C, Caudwell A, Lherminier J, Larrue J (1993) Attachment of the flavescence dorée pathogen (MLO) to leafhopper vectors and other insects. Ann Appl Biol 123, 611-622

Lefol C, Lherminier J, Boudon-Padieu E, Larrue J, Louis C, Caudwell A (1994) Propagation of flavescence dorée MLO (mycoplasma-like organism) in the leafhopper vector Euscelidius variegatus $\mathrm{Kbm} . J$ Inverteb Pathol 63, 285-293

Lherminier J, Courtois M, Caudwell A (1994) Determination of the distribution and multiplication sites of flavescence dorée mycoplasma-like organisms in the host plant Vicia faba by ELISA and immunocytochemistry. Physiol Mol Plant Pathol 45, 125-138

Lim PO, Sears BB (1989) 16S rRNA sequence indicates that plant-pathogenic mycoplasma-like organisms are evolutionarily distinct from animal mycoplasmas. J Bacteriol 171, 11, 5901-5906

Maurer R, Roux J, Seemüller E, Cousin MT (1994) Characterization of witches' broom MLO disease of poplar by a polymerase chain reaction $(\mathrm{PCR})$ that amplifies a sequence of the 16S rRNA gene and RFLP (restriction fragment length polymorphism). In : 10th Intern Congr Intern Organization for Mycoplasmology (IOM), Bordeaux, France, July 1926, 265

McCoy RE, Howard FW, Tsai JH et al (1983) Lethal yellowing of palms. Agric Exper Stn Institute of Food Agricultural Sciences, University of Florida, Gainesville, FA, Wood, Dean for research, November 1983. Bulletin 834. 1-100

Memane SA, Joi MB (1987) Identification of sources of resistance to little leaf of brinjal. J Maharashtra Agric Univ 12, 70-71

Mittempergher LA, Fagnani A, Ferrini F, D'Agostino G (1990) Elm yellows, a disease to be taken into consideration when breeding elm for disease resistance. In : Proceedings of the 8th Congress of the Mediterranean Phytopathological Union, Agadir, Morocco, 433-435

Neimark H, Kirkpatrick B (1993) Isolation and characterization of full-length chromosomes from non-culturable plant-pathogenic mycoplasma-like organisms. Mol Microbiol 7, 1, 21-28

Peferoen M (1992) Engineering of insect-resistant plants with Bacillus thuringiensis crystal protein genes. In : Plant Genetic Manipulation for Plant Protection (AMR Gatehouse, VA Hilder, D Boulter, eds), Biotech Agric 76, 135-155

Saeed E, Cousin MT (1995) The genetic relationship between MLOs causing diseases in the Sudan and different continents revealed by polymerase chain reaction (PCR) amplification of the 16S RNA gene followed by RFLP analysis. J Phytopathol 143, 1720

Saeed E, Sarindu N, Davis DL, Clarck MF, Roux J, Cousin MT (1994a) Use of polyclonal antibodies to identify mycoplasma-like-organisms (MLOs) from the Sudan and Thailand. J Phytopathol 142, 345349

Saeed E, Seemüller E, Schneider B et al (1994b) Molecular cloning, detection of chromosomal DNA of the mycoplasma-like organism (MLO) associated with faba bean (Vicia faba L) phyllody by southern blot hybridization and polymerase chain reaction (PCR). J Phytopathol 142, 97-106

Schvester D, Moutous F, Bonfils J, Carles P (1962) Étude biologique de cicadelles de la vigne dans les sud-ouest de la France. Ann Épiphyties 13, 205237

Seemüller E, Schneider B, Maurer et al (1994) Phylogenetic classification of plant-pathogenic mycoplasmas by sequence analysis of $16 \mathrm{~S}$ rDNA. 10th Intern Congr Intern Organization for Mycoplasmology (IOM), Bordeaux, France, July 1926, 224-225

Sharma AK, Cousin MT (1986) Mycoplasma-like organisms associated with the witches' broom disease of poplar. J Phytopathol 117, 349-356

Sharma AK, Savouré A, Rousseau J, Cousin MT (1986) Hydrangea virescence. II. Diagnosis by fluorescence microscopy and detection of infection in resin-embedded samples with bright field and phase contrast microscopy. agronomie 6, 255-263

Smart C, Sears B, Kirkpatrick B (1994) Analysis of evolutionary relationships between MLOs and other members of the class mollicutes based on $16 \mathrm{~S} / 23 \mathrm{~S}$ rRNA intergenic sequences. 10th Intern Congr Intern Organization for Mycoplasmology (IOM), Bordeaux, France, July 19-26, 269-270

Tang K, Davey MR, Blackwall NW et al (1994) Transformation of Japonica rice with an insect resistance gene driven by a phloem-specific promoter. Intern Congr Plant Molecular Biology, Amsterdam, June 19-24

Van Der Meer FA (1980) Witches' Broom in Poplars. Populier 17, 2, 42-43 